\title{
El fin del mundo fortificado y la aparición de las «aldeas abiertas». La evidencia del Centro-Oriente de Lugo (Samos y Sarria)
}

TOMÁs Rodríguez FERnÁndez

A lo largo de este articulo se espera apuntar de manera general el paso de un paisaje dominado por hábitats fortificados, que se corresponde con la Edad del Hierro, a otro de poblados o aldeas abiertas, característico de la Alta Edad Media, y antecedente inmediato del poblamiento tradicional del rural gallego. Aunque inicialmente se intentaba construir una explicación válida para la zona de estudio y sus límites inmediatos, dada la escala de los acontecimientos involucrados en el análisis del proceso, es posible darle una validez más general a la hipótesis central de este trabajo. Si bien han sido los contenidos que se explicitan en este artículo los que me han llevado a formular la hipótesis central, creo oportuno dejar para ocasiones futuras aspectos concretos que es preciso desarrollar y profundizar.

En los últimos años la denominada Edad del Hierro se ha visto sometida a cierta convulsión, y tras años de paciente espera e inactividad han aparecido enfoques e hipótesis nuevas que a su vez están originando diferentes puntos de vista sobre estos acontecimientos del pasado. En el norte de Portugal Manuela Martíns y especialmente Armando Coelho (Coelho 1986) sintetizaron todo un cumulo de datos que en desorden yacían en los museos, aportando este último autor una síntesis de gran valor, y ensayando interpretaciones e hipótesis que poco más tarde serán recogidas por otros autores. Luis Xulio Carballo ArCeo (CARBallo 1989 y 1990) han dado en Galicia un impulso necesario al estudio de los aspectos espaciales y económicos del mundo castrexo, estableciendo modelos de emplazamiento y captación de recursos que influyen en la localización de los hábitats. Este fenómeno, estudiado de forma diacrónica, aporta una seriación temporal del proceso, siendo observables diferencias en las diversas "fases". Si bien los autores citados fueron reactiva- 
dores de una investigación con claros y graves síntomas de «letargo intelectivo", rige todavía en sus construcciones históricas un excesivo hincapié en la dimensión económica del medio físico como factor determinante, desatendiendo su dimensión imaginaria y obviando que el proceso de percepción del espacio se percibe y representa de diversas maneras, sin que tenga exclusivamente el carácter unidimensional que tradicionalmente se le viene asignando (GODELIER 1986).

Al margen del tiempo de estudios enunciados anteriormente, y centrándose en el fenómeno religioso, Blanca García Fernández-Albalat (1990) ha formulado nuevas hipótesis acerca de la celticidad de la religión del área lusitano-galaica (investigación que entronca en la línea abierta por el profesor Bermejo Barrera). Será con dichas hipótesis cuando despunte la polémica sobre la diferente significación y alcance de los rasgos culturales célticos en el NW Hispano, disputa que enmascara el enfrentamiento entre diferentes posicionamientos teóricos. Una síntesis breve y a nuestro juicio "óptima" sobre la cultura castrexa puede leerse en Vázquez y Bermejo (1991).

Las periodizaciones de la Cultura Castrexa que se emplean en la actualidad (basadas fundamentalmente en artefactos y tipos de objetos diversos) parecen estar de acuerdo en que ésta desaparece, de modo más o menos acelerado, en la segunda mitad del siglo I d.D., provocada por las reformas Flavias (sintetizado en CARBallo 1989, 27-41). Se abre aquí la etapa de Romanización, concepto que aunque nunca ha sido suficientemente definido, en ocasiones es designado como un "fenómeno complejo" en el que se supone el paso de una cultura "indígena" a otra Galaico-Romana (ARIAS VILA 1992, 23), que incorporaría rasgos de ambas.

En realidad, el calificativo de "romanizado" se le atribuye a un yacimiento en función de la aparición en él de "cerámica romana", usualmente terra sigillata y/o tegulae. Desde este punto de vista es frecuente encontrar la expresión "castro romanizado" (entre otros MAÑANES 1981) para caracterizar a una comunidad que habita en un castro, y que ha adquirido por comercio cerámica de tipología romana o que imita modelos romanos. El comercio y sus mercancías se homologan normalmente a "romanización", y se establece un parangón significativo entre la intensidad de ambos, otorgándole al comercio de esta época características genuinas de sociedades capitalistas, y obviando que nuestra visión etnocéntrica de los hechos económicos nos lleva a buscar «espontáneamente" instituciones y funciones "económicas" separadas y diferenciadas de las relaciones sociales (Godelier 1989: 38). Apunta este autor que dicho proceder "impide entender las lógicas particulares de las sociedades no capitalistas» (GODELIER 1989: 48). 
Es sobradamente conocido que no son únicamente las "producciones" materiales las que definen a una Cultura, sino también sus "representaciones" (LÉvI-Strauss 1973: 322). Es en este sentido como creemos que se ha de entender el concepto de "romanización", es decir, no como una mera adquisición formal de modelos y manufacturas, sino como la aprehensión generalizada de valores culturales e ideológicos romanos.

De acuerdo con lo que se ha expuesto se puede establecer una relación íntima entre Cultura, Pensamiento e Ideología de una sociedad. Se trata de contextualizar los restos materiales categorizados como "documento" dentro de una ideología, o de una categoría de pensamiento (BERMEJo 1993b).

Dumézil reiteró su convicción de que la religión fue por mucho tiempo «la principal expresión de la ideología» (DUMÉZIL 1990: 24). Se nos presenta así la posibilidad de acceder a la ideología, y por tanto acercarnos a la Cultura por medio de la religión, pues ella es el origen de las "categorias fundamentales del pensamiento" (DURKHEIM 1982: 390), teniendo presente que "la sociedad ideal (reflejada en el mito y la religión) no está por fuera de la sociedad real, sino que forma parte de ésta" (DuRkHeim 1982: 394). La religión se comporta como un código simbólico que sirve para designar y regular funciones de lo cotidiano mediante símbolos o "equivalentes significativos del significado", es la "función simbólica, específicamente humana" (LÉVI-STRAuss 1973: 181-185). No sólo está conectada con la ideología, sino que al legitimar y regular los hechos trascendentes de la sociedad se conecta también con el poder, tal y como explica Gauchet (CLASTRES et al. 1980: 51-89).

Es nuestra opinión que fundamentalmente esta vía nos permite acercarnos a lo que realmente consideramos importante de una Cultura: su Pensamiento. Los rasgos generales de este pensamiento, o sus características, servirán para "contextualizar" en cierta medida el "documento histórico"; ya sea éste de naturaleza material o esté constituido por aspectos de espacialidad y/o visibilidad (CRIADO 1993). La construcción de este discurso se podrá realizar por medio de la "imaginación histórica" (BERMEJO 1991), abandonando así la pretensión de acceder a contenidos ideológicos del pasado desde postulados teóricos de corte empírico.

El trabajo de campo que nos sirve de base dio comienzo en el invierno de $1988^{1}$, después de haber sido seleccionada una zona de estudio

1 El proyecto de Actuación Territorial se desarrolló bajo el abultado título de Prospección Arqueolóxica e Estudio Etno-Cultural do Concello de Samos e Trece parroquias de Sarria (Lugo) y en él trabajaron (además del que suscribe) Ángel Acuña Piñeiro, 


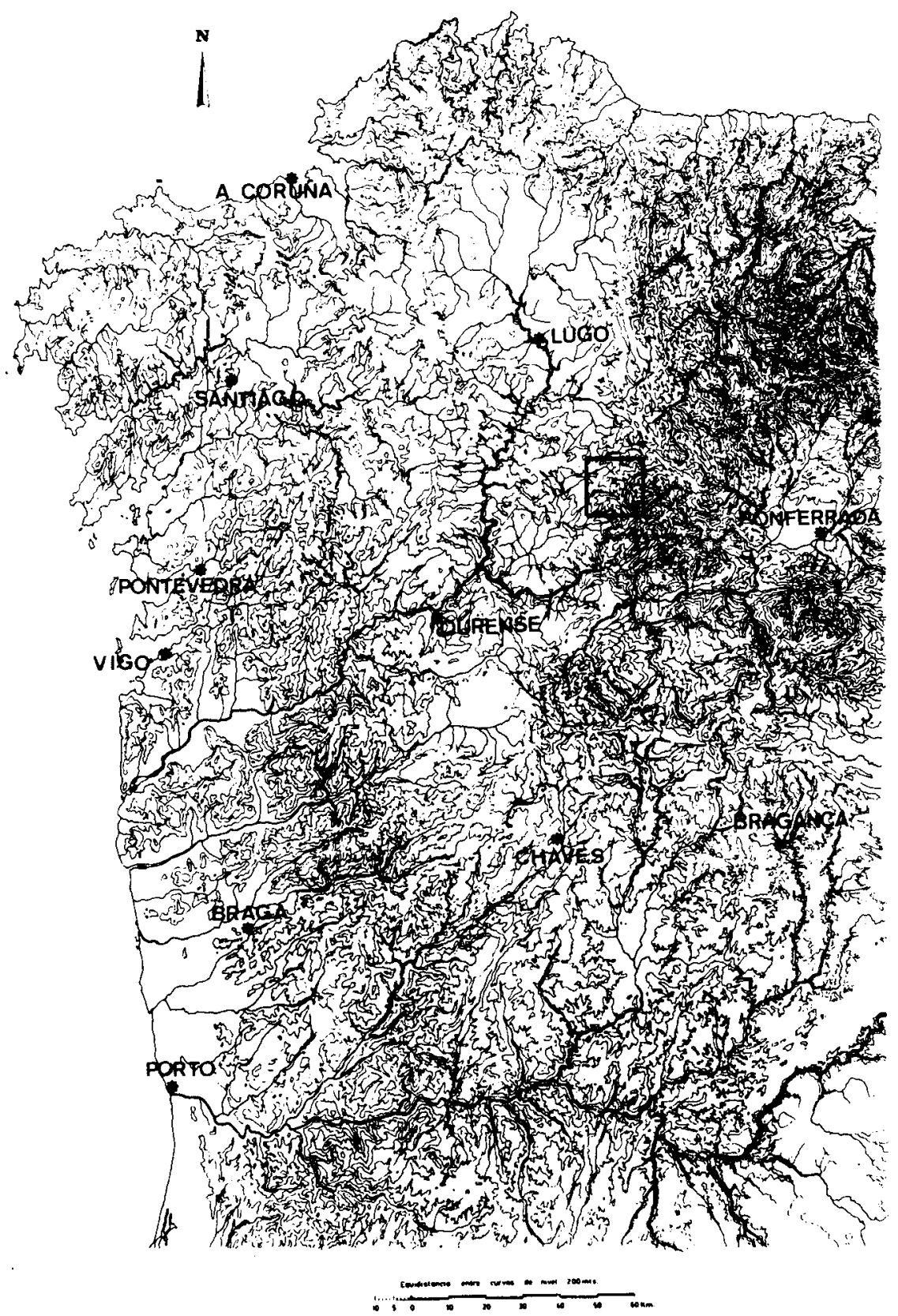

Fig. 1. Localización de la zona de estudio. 
en el sector oriental de la provincia de Lugo. Finalmente sería el área comprendida por el ayuntamiento de Samos y el oriente del de Sarria (fig. 1) la que poseia en mayor medida los requisitos necesarios para poder alcanzar los objetivos que nos proponiamos. En su primera fase se recogieron y trataron, entre otros, los datos arqueológicos que se refieren a las caracteristicas objetivas de los yacimientos (situación, tamaño, materiales, etc.). El tratamiento de estos datos fue abordado desde un punto de vista no convencional. De este modo al tratar aquellos aspectos referentes al paisaje actual y/o tradicional, y también al recoger información agrológica tal como valoración de clases de suelos y su uso tradicional, se acudió al código campesino tradicional. Intentábamos así liberarnos en cierta medida de una perspectiva urbana y cientificista a la hora de tratar aspectos que las sociedades campesinas no consideran desde nuestro particular punto de vista.

Al poder aprender directamente de los campesinos de esta zona valoraciones concretas se tiene la suerte de poder establecer un marco comparativo que podrá ser aplicado en el estudio de otras comunidades campesinas del pasado, y que contiene la virtud de ser un punto de vista no "urbano capitalista" y no cientificista ${ }^{2}$. Desde esta perspectiva las consideraciones que, por ejemplo, se deriven de nuestras charlas con los vecinos de estas aldeas acerca de las aptitudes del terreno para una determinada forma de cultivo y un grupo de plantas concretas, posibilitará su aplicación a otros grupos humanos que, viviendo en ese mismo espacio en épocas anteriores, cultivasen ese mismo grupo de plantas y empleasen una tecnología similar, pero nunca determinará que se puedan extrapolar directamente sus consideraciones. En este momento entra en juego la arqueología en toda su amplitud, pero con el añadido consecuente de buscar un marco de subjetividad contextual (HaBERMAS 1989) que se pueda aplicar a las comunidades que estamos considerando.

Aqui trataremos de comunidades que vivieron en poblados fortificados y también de grupos humanos que habitaron aldeas abiertas, es decir, dos realidades culturales diferentes como son los pobladores indo-

Juan Carios Castro Carrera, Ana Filguierias Rey y Juan José Perles Fontao. El proyecto estaba avalado por el Departamento de Historia I de la Universidad de Santiago de Compostela, y subvencionado por la Dirección Xeral do Patrimonio Histórico e Documental de la Xunta de Galicia. Una primera noticia de este trabajo ha sido publicada en Rodriguez Fernández, T. (1991).

2 Es significativo que en Galicia, cuando la Administración decide eliminar el paisaje tradicional para crear otro más "racional y moderno" al que se le llama Concentración Parcelaria, surgen múltiples disputas en la valoración de las tíerras entre los ingenieros y los agricultores (campesinos y granjeros), pues lo que para unos es óptimo para el otro es pésimo. Consideraciones similares pueden verse en Criado 1989: 101. 
europeos de la Edad del Hierro y los campesinos cristianos de las villae o vici de la Baja Romanidad y Alta Edad Media. Esta desemejanza general que observamos entre ambas realidades en lo referente a la construcción del paisaje o a la ordenación del espacio y del territorio, se fundamenta en dos concepciones ideológicas del mundo diversas, que se ejemplifican en la religión de cada una de ellas.

Se podrá criticar de este trabajo la escasa mención que se hace de lo Romano como elemento cronológico que se interpone entre la Edad el Hierro y la Alta Edad Media, sin embargo hay que indicar que estos conceptos generales de la Historia no siempre se acomodan a la realidad cultural, es decir, si bien cronológicamente se puede segmentar el lapso de tiempo que trata de abarcar este trabajo en "antes" de la conquista (Edad del Hierro), "durante" la conquista y "ocupación" (Época Romana Imperial o Galaico-Romana) y "después" de la caída del Imperio (Alta Edad Media), creo que (y aquí está la base de mi hipótesis) como manifestación cultural sólo tenemos dos momentos definidos y un tránsito, tal y como, por otra parte, se puede observar en el comportamiento espacial de los yacimientos de esta época, es decir, que en la zona de estudio, aparentemente, no hay rasgos estructurales de romanización, aunque lógicamente sí existen testimonios, documentos arqueológicos coyunturales, de esta presencia romana. Tal y como recoge Lévi-Strauss cada orden social implica al que le precede, pero el tránsito de una a otra está marcado por una discontinuidad significativa (LÉvI-STRAUUS 1983: 53).

Como se ha expuesto anteriormente nuestra hipótesis es que tan sólo un cambio en la ideología, representada por la religión, es capaz de producir un cambio general, un cambio cultural, extremo éste que por otro lado parece bastante obvio. Desde este punto de vista determinados "documentos arqueológicos" tales como minas de época romana o determinados hábitats fortificados asociados con ellas son testimonio de una coyuntura política a gran escala, y explicitan la presencia de intereses romanos en la zona, pero esta presencia no llegó a incidir de forma suficientemente contundente como para producir la "aculturación" de los habitantes de los castros.

A continuación trataremos de establecer, partiendo de los resultados de la prospección superficial, un límite temporal de "uso como habitación" para los hábitats fortificados. Seguidamente pasaremos a valorar las evidencias de la ocupación romana, y finalmente se tratarán algunos yacimientos abiertos de época altomedieval de los que tenemos documentación arqueológica o escrita. 


\section{ALDEAS FORTIFICADAS; LA EDAD DE HIERRO DESPUES DE AUGUSTO}

No conviene olvidar que todos los datos "inéditos" que poseemos de esta zona proceden exclusivamente de la prospección, factor que podrá relativizar en cierta medida algunas de las consideraciones que se hagan.

La hipótesis que se construye aquí es que en esta zona concreta la romanización, entendida ésta como aculturación de una comunidad determinada por la ideología romana, no llegó a afianzarse, es decir, lo romano está socialmente representado, pero no culturalmente arraigado; o lo que es lo mismo, después de más de trescientos años de la conquista de Augusto no se consolidó entre el campesinado de esta zona una forma de vida romana bajo ningún punto de vista. Aunque esta hipótesis puede ser válida a nivel general para las zonas rurales del interior, tampoco debe ser sacada del marco espacial al que se circunscribe este trabajo, pues la reconstrucción que puede hacerse para áreas periurbanas o para la Galicia costera u otras zonas puede ser, seguramente, contradictoria con ella.

Las características que presentan los castros de esta comarca y que aquí interesan señalar son las comunes a la generalidad en el NW, es decir, se asientan en zonas de límite entre el labradío y el monte, o si se prefiere la terminología de los campesinos actuales (ya documentada en época altomedieval) entre las tierras "frias y calientes", es decir entre aquellas de suelos pesados y espesos, poco aireados, que retienen excesivamente el agua y que se resisten al arado; frente a las "calientes", o aquellas que cuentan con suelo ligeros, con buena capacidad tanto para absorber como para drenar aguas, en las que el aire puede circular, aireándolas, y que son más dóciles al arado y a la herramienta. En las "frias" se asientan los prados, los bosques y el cultivo intensivo de labradío (con ciertas modificaciones que tienden a "calentarlas"), en las "calientes" está el monte (para abonado y pastoreo) y el cultivo extensivo y de roza de cereal. Ambas son necesarias, y las dos fueron cultivadas por aquellos que establecieron sus fortificaciones en lugares con fácil acceso a ambas tierras.

Junto a esta caracteristica aparece la capacidad defensiva del lugar, bien intrínseca al sitio elegido o bien casi totalmente construida. Puede variar entre unos emplazamientos y otros el predominio del factor defensivo o del agrícola, pero siempre el resultado es un poblado fortificado, suficientemente defendido, y cercano a ambas clases de tierras. Si el factor determinante fue el defensivo el castro normalmente estará más en zona de monte que de labradio, y entonces será necesario construir esas zonas de cultivo intensivo con el aporte de tierras, aterrazando 
("tendiendo a enfriar" estas tierras de monte); si lo determinante fue la aptitud agrícola del lugar se construirán murallas, fosos y parapetos suficientes para logar un hábitat satisfactoriamente fortificado.

Esta ubicación liminar, con acceso a tierras "frías y calientes", a los dos principales dominio agricolas que pueden ser explotados por una agricultura tradicional como la que es posible documentar a través de la memoria oral en esta zona, es una característica común a los castros y a las aldeas actuales, tal como a señalado Criado Boado basándose en apreciaciones de Bouhier; aquel autor apunta además la posibilidad de que "en ese momento - Edad del Hierro- el paisaje gallego adquiriese una morfología que se mantuvo en lo esencial hasta la Baja Edad Media, madurando progresivamente el sistema" (CRIADO 1989: 91). El sistema agricola maduro se corresponde para este autor con el paisaje tradicional gallego, que empieza a desarrollarse a partir del siglo xIII.

En la zona de estudio se han catalogado en total 34 castros (fig. 2), algunos de los cuales serán tratados en el apartado siguiente. De la globalidad de los asentamientos fortificados que hemos reconocido es importante señalar que de aquellos que poseen material arqueológico en superficie (cerámica) asignable con cierta precisión a una época concreta, la mayor parte de ellos proporcionan cerámicas tardías, imitación de modelos romanos, que pueden ser datadas sin dificultad en los siglos $\mathrm{IV}-\mathrm{V}$ y que incluso se pueden prolongar hasta los siglos v-vi d.C. ${ }^{3}$. Por lo que respecta a las cerámicas de tradición indígena, dada la parquedad de datos procedentes de excavaciones en el entorno de la zona de estudio, sólo se puede indicar que el material de superficie es "tardío o muy tardío" 4 . Desde la sesgada perspectiva que pueden proporcionar estos hallazgos de superficie, y teniendo por lógico que esta cerámica se corresponda con los últimos niveles de habitación del poblado, quizá se podría apuntar para esa zona un momento tardío para el abandono del hábitat fortificado, momento que podría ser datado en torno al siglo $\vee$ d.C. para un buen número de castros. Se podría pensar que en estos momentos tardíos sólo un grupo minoritario de gente habitaria estas "fortalezas", sin embargo la frecuencia y cantidad de material de este tipo, hallado tanto en el interior de los recintos castrexos como en sus inmediaciones, sugiere algo más intenso que una ocupación esporádica, y apunta a que casos

\footnotetext{
3 Agradezco al doctor D. Juan L. Naveiro López las consideraciones acerca de la cerámica de "tradición romana", así como una aproximación cronológica a la misma.

"Las consideraciones sobre la cerámica de "tradición indigena" que se ha recogido en superficie se deben a la doctora Pepa Rey Castiñeiras, a la que agradezco su atención, asi como sus consideraciones.
} 


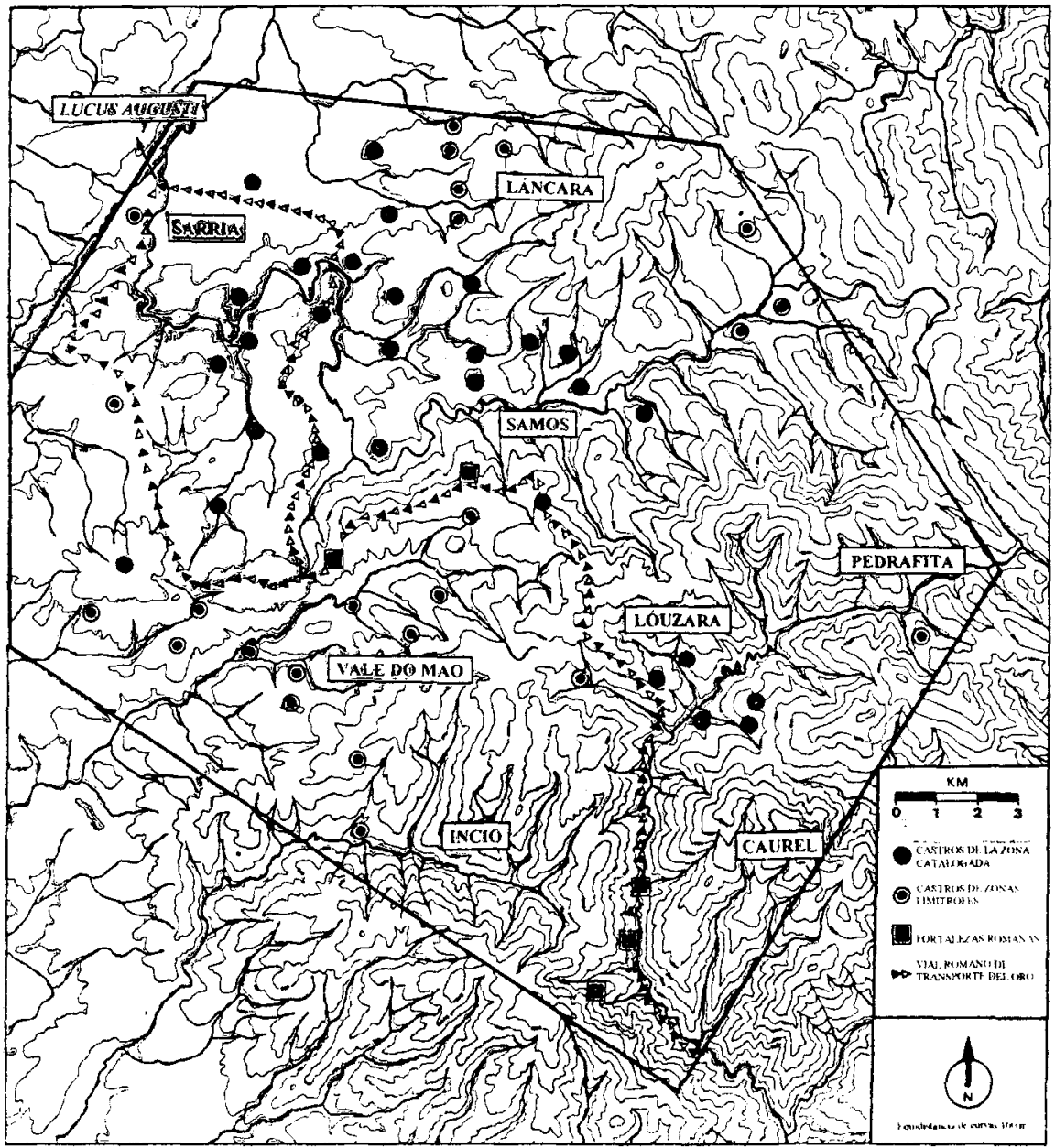

Fig. 2. Mapa topográfico con la indicación de lugares y comarcas citadas en el texto. Se indican, asimismo, los yacimientos fortificados y el vial romano de transporte del oro. 
como el conocido del Castro de Viladonga forman parte de la "norma" y no de la excepción. Ello implica la perduración generalizada de estas características bien definidas como propias de la Edad el Hierro en pleno siglo IV-V en la zona centroriental de Lugo, y sin que en absoluto se pretenda que esta realidad se generalice o se extrapole a otras zonas, sí que puede ayudar a comprender otros casos como Castromao, Castillós, Coaña, Briteiros, Mohías, etc., donde, como es sobradamente conocido, se han documentado en algún caso perduraciones de incluso hasta el siglo vi. Así parece que esta "pervivencia" de lo indígena llega a conectar con la época germánica, traspasando el primer cuarto del siglo $\mathrm{v}$, momento en que comienzan a asentarse en el NW los Suevos ${ }^{5}$.

\section{LA PRESENCIA ROMANA: EL ORO Y LA ESPADA}

Evidentemente esta zona no estuvo libre de la presencia romana, pues tal y como se ha indicado anteriormente, lo romano estaba aqui socialmente representado. Sin embargo, sólo un yacimiento ejemplifica el "modo de vida romano", únicamente en la conocida villa de "Vilar de Sarria" podemos decir que lo romano está culturalmente arraigado. El resto de los yacimientos que estructuralmente no parecen ser de concepción totalmente indígena en cuanto a emplazamiento y a su concepción territorial son o bien minas auriferas o bien castros o asentamientos fortificados relacionados con ellas.

Aunque en las proximidades de esta zona existen otros yacimientos que pueden ser catalogados como "romanos" 6 todos ellos parecen pertenecer a un momento tardio (Bajo IMperial). La villa de "Vilar de Sarria", ubicada en la periferia de nuestra zona de estudio, puede ser algo mejor

5 Esta perduración es generalmente "consentida" por los arqueólogos, aunque en numerosas ocasiones se infravalora su significación estructural tanto en el proceso de Cambio Cultural, como en la creación de un nuevo paisaje y una nueva estructuración del territorio. Las implicaciones que tiene el acontecimiento histórico de la perduración tan contumaz de modos de vida supuestamente "pretéritos" (basado en segmentaciones cronológicas extraídas de materiales arqueológicos y en acontecimientos globales) le otorga una singular importancia histórica a la que no parece ajustarse el adjetivo de "ăhistórico" con el que diversos autores lo han calificado (FARIÑA Y SUÁREZ 1988: 61-62).

6 Conocemos la existencia de otros yacimientos que pueden ser catalogados como romanos o como altomedievales. Se trata de yacimientos abiertos que proporcionan, como única guia para asignarles una adscripción "crono-cultural" fragmentos de tégula. Algunos de ellos fueron identificados como despoblados medievales tras la consulta y estudio del "Tumbo de Samos". De todos modos, existen yacimientos sobre los que existen dudas, aunque ninguno de ellos se halla dentro de la zona que estamos considerando en este trabajo, sino que se ubican en sus inmediaciones. 
caracterizada gracias a una serie de antiguos hallazgos: fustes, molinos, ladrillos, sepulturas y sobre todo la "Estela de Vilar de Sarria». Esta estela ${ }^{7}$ aparece reseñada en abundante bibliografía, si bien seguiré al profesor Acuña Castroviejo, por ser este autor quien ha prestado una mayor atención a dicha estela, recogiendo y sintetizando crícamente opiniones anteriores (ACUÑA CASTROVIEJO, F., 1976). Basándonos fundamentalmente en dicha estela se puede datar esta villa entre los siglos III-IV, datación en la que están de acuerdo la mayoría de los autores que la han estudiado.

Esta fecha se muestra coherente con la tónica general de este tipo de yacimientos en el NE; pues las villas alto-imperiales son escasas en relación con las de época bajo-imperial, que constituyen la mayoría, y para las que se acepta una cronología del siglo $\mathrm{N}$, datación que consideraremos válida también para nuestro caso.

Este tipo de yacimiento romano, escasamente representado en la zona escogida, parece tener una continuación en época medieval, llegando hasta nuestros dias. Sobre el mismo yacimiento (o en todo caso inmediato a él) se construyó la iglesia de O Salvador de Vilar de Sarria, "capital" de una de las mayores parrqouias del ayuntamiento ${ }^{8}$. Si bien el hecho de que en un mismo lugar se halle la iglesia de Vilar de Sarria (y el lugar de Airexe), y la villa bajo-imperial no implica indefectiblemente que exista una continuidad del hábitat, asi será considerado a modo de hipótesis.

El resto de los yacimientos que se pueden considerar "romanos" son todos asentamientos fortificados y minas auríferas, y en ellos no se per-

Aparece descrita del siguiente modo en Acuña Castroviejo (1976: 108): "En el anverso se representa una pareja de figuras togadas, de cabezas irreconocibles a causa del deterioro. Los cuerpos se cubren con ropajes labrados (...) dejando las manos al descubierto. (...). En el reverso (...) aparece una embarcación con la proa rematada en mascarón, con un mástil y los cabos para sujetar el velamen. Dentro hay cuatro personas de las que casi no se ve más que las cabezas; una al lado de la popa y las otras tres mirando para ella. Debajo de la embarcación hay un delfin, y en la parte superior derecha un águila con las alas abiertas y posada encima de un objeto que muy bien podria ser una roca, aunque otras interpretaciones quieren ver aqui un águila cogiendo un pez entre sus garras." El reverso de esta estela se consideró tradicionalmente que representaba el mito de Ulises y las Sirenas, Acuña Castroviejo, en el citado artículo, desecha esta interpretación, sobre todo porque en esta estela "se observa con claridad que faltan los elementos "clásicos" de la representación del tema: Ulises y las Sirenas".

8 Resulta llamativo el gran tamaño de la parroquia $\left(6,2 \mathrm{~km}^{2}\right)$ para lo que es normal en zonas de llanura. Las parroquias limítrofes con la de O Salvador de Vilar de Sarria, que comparten con ella una fisiografia similar, son todas de muy inferior tamaño. A modo de ejemplo, se puede decir que la mayor de ellas tiene $3,7 \mathrm{~km}^{2}$, concretamente las de San Sadurniño de Ferreiros y la de San Xullao de Veiga. La menor es la de Santiago de Castelo dos Infantes, con $1,9 \mathrm{~km}^{2}$. La media de las parroquias del entorno es de $2,8 \mathrm{~km}^{2}$ y la superficie media de la parroquia en el ayuntamiento es de $3,7 \mathrm{~km}^{2}$. 
cibe una pervivienciad el hábitat o del emplazamiento en épocas posteriores, a excepción del Castro de Parada, como se verá más adelante.

Los yacimientos fortificados que consideramos de construcción romana cuentan todos con unas caracteristicas comunes:

1. Invariablemente están localizados en tierras de monte, algunos en zonas muy agrestes y en todos los casos a una considerable distancia de las tierras de labradio, o tierras que lo posibilitarian.

2. Guardan todos una intima relación con el camino antiguo que une O Caurel con la depresión de Sarria y Monforte, por donde presumiblemente discurria el vial romano que unía Lucus y Dactonium, en territorio de Lemos.

a) Esta relación puede ser física, haciendo que, al igua en $\mathrm{O}$ Caurel, el camino discurra por las inmediaciones del propio castro, o incluso por su mismo foso como en el caso de A Roda do Castro de Parada.

b) La relación también puede ser de control visual del camino y su entorno, aparte de un control casi total de la zona en la que se ubica; como caso paradigmático tenemos A Casa dos Mouros, y como excepción A Roda de Castrofeito, que parece ser más bien un lugar de cambio de animales de tiro en el camino, o alguna otra labor infraestructural, que un puesto de control.

c) En otros casos ambas características están unidas, como ocurre con el Castro de Formigueiros y Cividade do Castro da Margarita.

3. Por otro lado, esta serie de castros están conectados entre sí visualmente, de modo que, siguiendo el camino, desde un yacimiento se observa algún otro, y el vial es siempre observado por algunod e ellos.

4. Todos ellos están "superdefendidos" si se comparan con el resto de los yacimientos, así la mayoría posee piedras hincadas (Castro de Formigueiros, Cividade do Castro da Margarita y A Casa dos Mouros), totalmente ausentes en los castros que no pertenecen a este grupo. Algunos tienen torreones de diversa envergadura (fig. 3), y cuando su posición fisiográfica no les atribuye cierta inexpugnabilidad (que sí es total en el caso de A Casa dos Mouros) los fosos, parapetos y piedras hincadas se multiplican espectacularmente, llegando a una serie de seis en el Castro de Formigueiros (fig. 4).

Esta serie de características, al tiempo que reúne a estos yacimientos en un grupo homogéneo, los aleja también de los yacimientos típicos de la Edad del Hierro, o si prefiere indígenas o castrexos; solamente la intervisibilidad es un aspecto común a ambos grupos. A pesar de ello estos hábitats "romanos" adoptan la configuración de "castro", es 

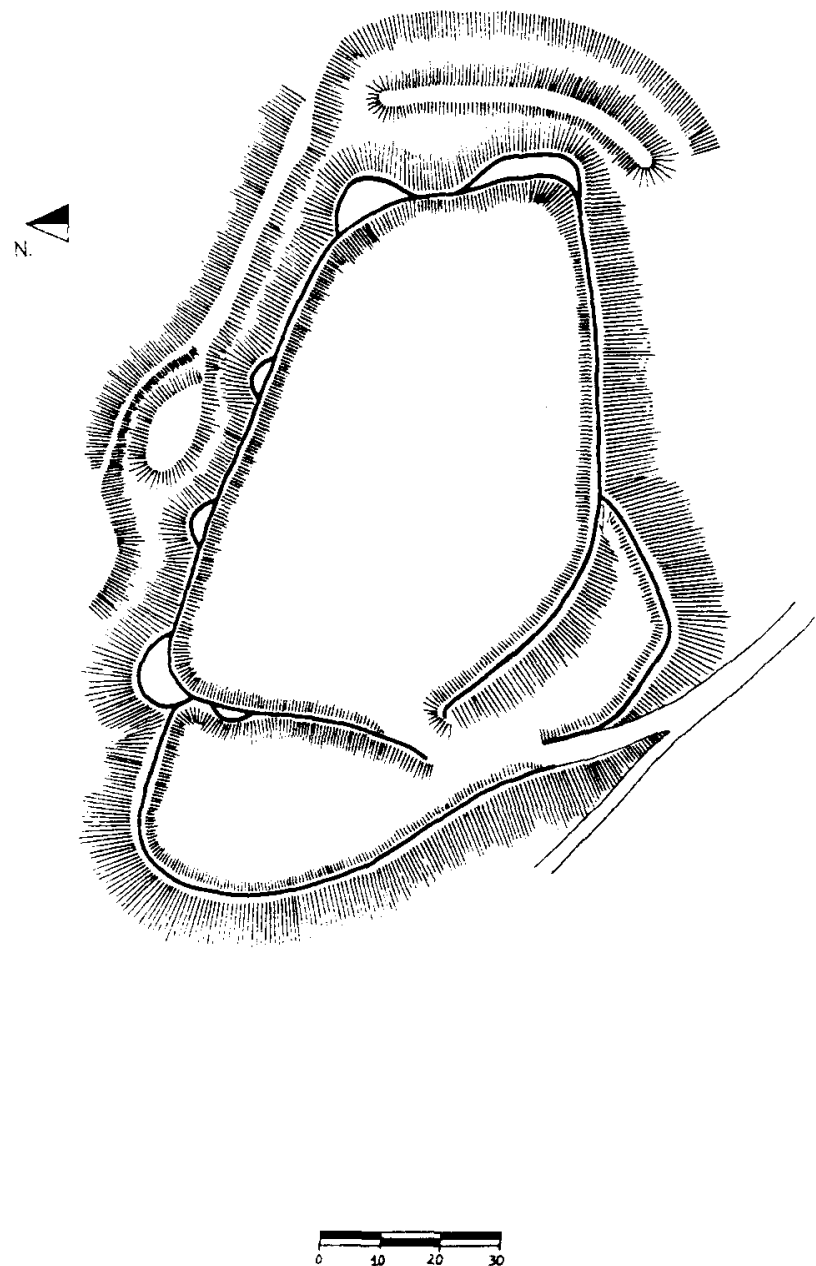

Fig. 3. Castro da Margarita, ejemplo de fortaleza romana con torreones defensivos. La linea gruesa continua indica los tramos de muralla visibles (croquis de Juan José Perles Fontao).

decir, se ordenan como un núcleo habitado aislado y separado de su entorno inmediato por una sucesión de fosos y murallas, conformando una superficie construida destinada a la defensa que incorpora elemen- 

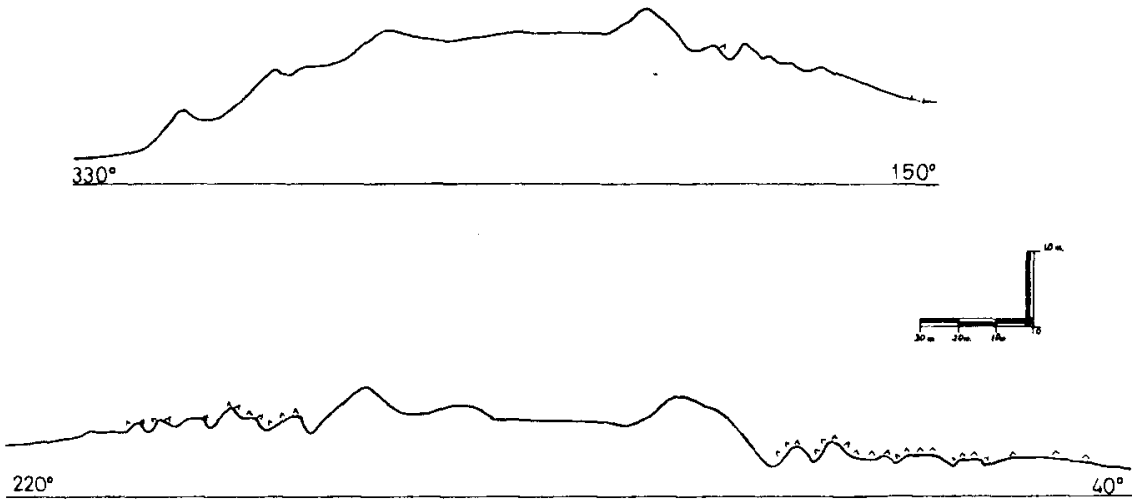

Fig. 4. Cortes del Castro de Formigueiros donde se aprecian sus elementos defensivos. Los triángulos indican áreas de piedras hincadas.

tos foráneos como las piedras hincadas o los torreones; pero que en esencia es el "castro convencional" tomado como modelo y "optimizado" como hábitat fortificado, es decir es un "castro superdefendido". Sin embargo, estas innovaciones defensivas y coactivas no fueron imitadas por los indígenas.

Los factores agricolas parecen estar ausentes en su ubicación, y se emplazan en lugares donde no es fácil realizar una agricultura intensiva, y en algún caso donde es improbable incluso cualquier cultivo, como en la posible turris de A Casa dos Mouros. El factor que parece totalmente determinante es el defensivo-coactivo, no sólo del yacimiento en sí, sino de la red de infraestructuras que tiene su núcleo en el vecino Caurel, ante el cual las caracteristicas agrícolas de su terreno circundante son una especie de "valor añadido" aleatorio. Este hecho puede tener su explicación por ser estos yacimientos eminentemente militares, como parece suceder en O Caurel (LuZÓN Y SÁNCHEZ-PALENCIA 1980: 104). Esta diferencia pudo ayudar a cierta integración de los grupos de guerreros castrexos en las unidades militares romanas (García Fernández-Albalat 1990: 22), pero también evita el conflicto sobre la explotación de terrenos agrícolas e incluso ganaderos, que permanecen libres de ocupación y explotación romana directa, aunque bajo su control y administración.

Dicho grupo de yacimientos de edificación romana (y quizá también algún otro de época anterior) parecen comportarse funcionalmente como puntos de engranaje del sistema militar que asegura la eficacia del pro- 
ceso de dominio y explotación del territorio; desde esta perspectiva son "objetos útiles", con una finalidad funcional claramente denotada. Si adoptamos un punto de vista algo más amplio habremos de aceptar que ésta no se limita a la simple utilidad práctica inmediata, sino que además su función se extiende a toda una serie de aspectos comunicativos que se derivan del carácter simbólico que posee, o puede poseer, cualquier objeto útil. Estas funciones comunicativas, o simbólicas (connotadas) no son menos útiles o importantes que aquellas otras funciones pragmáticas (denotadas) ${ }^{9}$. Desde esta perspectiva el poblado fortificado no sólo tiene como "función" la inmediata utilidad práctica de "defender", sino que además existe la finalidad comunicativa connotada de "coaccionar", "disuadir" o de "mostrarse fuerte". Esta emisión de información es generada por las "defensas" del poblado, o aquel espacio arquitecturado que no se "usa" como vivienda colectiva, sino como separación entre el territorio accesible y global del "exterior» y el espacio grupal privado del «interior». Es éste un Espacio de Interdicción que impide o condiciona el contacto entre dentro y fuera, multiplicando los elementos defensivos y estableciendo de este modo una banda de redundancia sobre la base del "modelo indigena». Así, al mismo tiempo que aumenta la "eficacia física" de la fortaleza lo hace también su «eficacia simbólica", y se traspasa su función denotada de defensa estática para actuar como un elemento dinámico de coacción y disuasión. El emplazamiento escogido, dominando amplísimas panorámicas, y al tiempo haciéndose presente de modo constante en el paisaje, añade una nueva banda de redundancia al mensaje. En resumen, se puede decir que este grupo de "fortalezas romanas" no sólo actúan como bastiones defensivos estáticos del transporte del oro y del poder de Roma, sino que además funcionan simbólicamente como elementos activos de coacción.

A lo que se acaba de señalar había que adjuntarle otras consideración, ya que se puede señalar que dichos poblados tienen la virtud de representar metafóricamente el sometimiento a un Poder cuyo "centro" es en gran medida intangible, ya que no en vano una de las consecuencias de la conquista es que lo "indígena" pasa de ser centro a ser periferia, de autorreferenciarse a hacerlo en función de otros, con todo lo que ello conlleva.

Esta "violencia simbólica" puede apreciarse también en otros ámbitos. Por una parte, es notorio que se produce una apropiación del camino (o

9 Estos conceptos, desde el punto de vista de la semiótica a nivel general, aparecen en Eco, U. (1972). Su aplicación a casos concretos de la Edad del Hierro y poblados fortificados de época romana, asociados a minería, puede consultarse en RodRíGUEZ FERnÁNDEZ, T. (1991). 
incluso creación del mismo en parte), evidenciado no sólo por el intenso control al que se somete, sino también porque se construyen poblados sobre él, haciendo discurrir el vial por el foso o por las inmediaciones de la fortaleza y convirtiéndolo asi en una prolongación de la misma. La disposición sobre el territorio de los poblados fortificados romanos es tal que cualquiera que circule por el camino podrá ser observado y controlado perfectamente. Queda patente pues que el camino "es propiedad" de Roma. Si bien el camino es o puede ser por sí mismo un lugar de especial significación religiosa para el mundo indígena (BERMEJO BARRERA 1986: cap. VII), creemos que se produjo otra acción que pudo generar en alguna medida dosis de "violencia simbólica", a saber: en la zona de estudio solamente el Castro de Formigueiros y el Castro da Margarita, ambos pertenecientes al grupo de los yacimientos romanos, comparten el espacio inmediato con túmulos megalíticos. La vinculación o relación espacial "intima" entre túmulos y castros en el NW es excepcional, y a estos se ha de añadir el que no se hayan encontrado evidencias, $O$ al menos indicios, de que en la Edad del Hierro se destruyesen o expoliasen túmulos. Aunque estos hechos no implican necesariamente que los túmulos funerarios erigidos por otras culturas tuviesen una especial significación dentro de la Cultura Castrexa; y a sabiendas de que este factor, como valor añadido, puede ser casual; es sin embargo oportuno tener en consideración el fenómeno conocido en las Islas Británicas por Invención de la Tradición (BRADLEY 1987). Con este término se expresa la reutilización simbólica de monumentos erigidos por culturas anteriores (v.g. Newgrange - Tara (durante la Edad del Hierro. En el caso de que en esta zona las extensiones ocupadas por túmulos tuviesen una especial significación religiosa que implicaba el tabú de habitarlas, o de construir en ellas hábitats, reservándose estos espacios para otras actividades, el hecho de que alguien contravenga la norma y desoiga la religión denota también un acto de violencia simbólica, y si además esta situación anómala se mantiene, entonces se convierte también en una metáfora de la dominación.

Quiero expresar con las líneas precedentes que además de las evidentes funciones prácticas de orden militar que poseen los yacimientos de esta "línea defensiva" existen otras funciones de carácter simbólico que son tanto o más importantes para el óptimo funcionamiento del proceso.

Por lo que se refiere a la minería, hay que indicar que en general las minas se abren en escarpes o fallas, en zonas de poca utilidad agricola o ganadera, y en el caso del Valle de Lóuzara es curioso observar cómo el valle aparece dividido en dos partes, una, al norte, ocupada por asentamientos castrexos, donde éste es más abierto y utilizable desde el punto de vista agricola y ganadero; y otra al ser, donde el valle es muy encaja- 
do, con un fondo estrecho y delimitado por fuertes escarpes. Es en la zona sur de este valle donde se sitúan tres de los cinco asentamientos fortificados romanos existentes en toda el área considerada (Casa dos Mouros, Roda de Castrofeito y Castro de Parada). Esta diferente aptitud agricola viene confirmada por la desigual distribución de las aldeas tradicionales en el valle, dos en el sur frente a más de quince en el norte, tres "castros romanos" ${ }^{10}$ en el sur frente a cinco "yacimientos castrexos" al norte.

Los otros dos yacimientos romanos de la zona (Castro de Formigueiros y A Cividade do Castro da Margarita), cuyas características arquitectónicas formales y funcionales, su emplazamiento, visibilidad, etc., hacen que formen entre si un conjunto desde todos los puntos de vista, se hallan también aislados del resto de los yacimientos, ya que están ubicados en zonas de monte, al borde de un escarpe, y observando entre ambos la totalidad de los "asentamientos castrexos" del entorno a media distancia.

Se puede admitir que esta serie de yacimientos están en función del control del transporte del otro desde su lugar de extracción en el inmediato Caurel y el propio valle de Lóuzara hacia la depresión de Sarria. El control de cada tramo de esta vía de comunicación parece estar complementado con otros yacimientos de apariencia más «indígena", como puede ser el caso del Castro de Escanlar "1, por cuyo foso discurre la vía a la que nos estamos refiriendo. La rotundidad con que se defiende este "camino aurifero" hace que sea plausible pensar que alguien ponia dificultades, o que de alguien se esperaba que las pudiese poner. La contundencia de la defensa implica la existencia de una previsión de ataque. Esta vía de transporte confirma la suposición de Luzón y SánchezPalencia (1980: 72, 74), pues proveniente d ela confluencia del Valle del Lóuzara con el Valle del Lor se adentra en Samos camino de la vía que de Lucus se dirigia a Dactonium (fig. 5), según las Tablas de Barro de Astorga. Parece que estamos ante una zona marginal de lo que fueron

10 De modo estricto no se pueden considerar los tres yacimientos como castros en el sentido de hábitat. Solamente A Roda do Castro de Parada puede ser considerado como un lugar de habitación, los otros dos parecen tener diferentes funciones. Así A Roda de Castrofeito parece estar más bien en relación con algún tipo de infraestructuras relacionadas con la via que evacua el oro de O Caurel hacia la depresión de Sarria y Monforte; por su parte, A Casa dos Mouros se puede considerar como un puesto de vigilancia a gran distancia, una turris que ejerce un gran control visual, y donde las características de la habitación no permiten asignarle con propiedad el calificativo de "hábitat".

1 El Castro de Escanlar, por sus características morfológicas, entra de lleno en el grupo de fortalezas castrexas; sin embargo, su situación fisiográfica y su emplazamiento ligado intimamente al camino nos hacen sospechar que se tratase de una pieza más del entramado militar inherente a la explotación aurifera. 
las explotaciones auriferas a gran escala de $O$ Caurel, pues las minas que hemos documentado en el ayuntamiento de Samos son de escasa envergadura, e incluso alguna puede ser que no pase de una simple cata para calibrar la riqueza en oro del mineral.

Se han documentado en total cuatro explotaciones de "cierta" significación, tres de ellas sobre yacimiento primario (Castro de Parada, As Grelleiras y O Rebolado) y una sobre yacimiento secundario (Cabanelaso, todas en las inmediaciones del área fisiográfica de $O$ Caurel. De aquellas que fueron explotadas siguiendo las vetas de cuarzo del yacimiento primario dos se excavaron en galería, y la otra fue realizada mediante una "corta".

Creemos que estas explotaciones, por lo menos las que se abren en galería, no pasan de ser meras calicatas para valorar la riqueza en oro de los filones de cuarzo, buscando una posible "veta aurífera». Algo similar pudo suceder en Cabanelas, donde el grosor del sedimento que potencialmente contiene oro es excesivamente delgado. Únicamente la mina del Castro de Parada puede ser considerada, a nuestro juicio, como tal. Desde este punto de vista esta zona limitrofe con O Caurel actuaría más como vía de transporte y comunicación que como zona de extracción de mineral.

Teniendo en cuenta la cronología de este conjunto de yacimientos que evidencia la presencia romana en la zona, podemos establecer dos momentos: uno de ellos es el que se circunscribe al momento de "explotación aurifera", incluyendo en él tanto minas como "infraestructuras" y otro, más tardío, que se corresponde con la villa de Vilar de Sarria.

Luzón y Sánchez-Palencia indican que la explotación a gran escala de las minas de O Caurel habría que llevarla sobre todo al siglo II. Para la zona que nos ocupa aceptamos dicha cronología al considerar que el entramado militar romano que observamos aquí forma parte de ese otro mayor que se centra en $O$ Caurel. Es también lícito suponer un abandono o decadencia total de estas explotaciones en el siglo III. De este modo, y en sentido amplio, se puede establecer un lapso de tiempo que iria desde momentos «inmediatos" a la conquista hasta el siglo $\mathrm{II}$, durante el cual la presencia romana en la zona fue activa y constante, sin que pretendamos insinuar que después de este momento la zona fuese abandonada por parte de Roma. Lo que parece ocurrir a partir de ese momento es el final de un modelo de ocupación y explotación del territorio, y tras un lapso de tiempo (que puede ocupar un siglo), se establece el segundo modelo, que es el de la villa, pobremente representada numéricamente en esta zona en Vilar de Sarria, yacimiento que ya hemos visto que no es anterior al siglo III. 

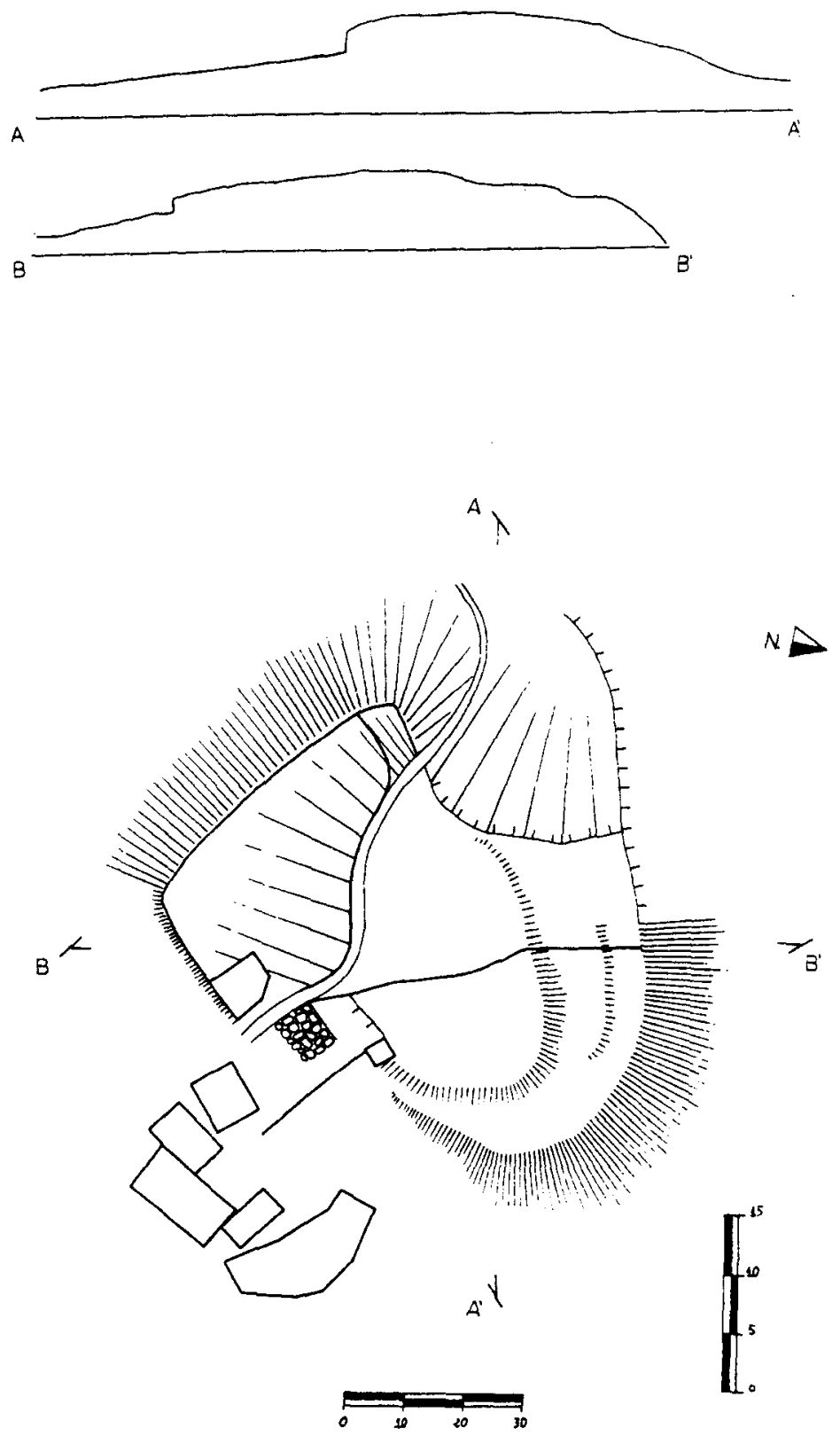

Fig. 5. Castro de Vila do Castro, ejemplo de continuidad del hábitat sobre el yacimiento castrexo. Obsérvense las construcciones actuales sobre los restos del castro (croquis de Juan José Perles Fontao) 
Estos dos modelo coyunturales de ocupación tienen una muy diferente significación estructural como veremos a continuación:

El primero de los "modelos" se puede calificar de "estatal" porque está promovido, financiado y ejecutado por el Estado para satisfacer necesidades estatales. Es un modelo cuyo objetivo principal es el control y dominio estratégico del territorio para de este modo optimizar el beneficio que se deriva de la conquista de una zona rica en oro. Para ello se procura el dominio de la vía de comunicación con Lucus, por lo que las fortalezas se emplazan en función de este camino, sobre el cual ejercen un control absoluto en el que posiblemente colaborasen "castros indígenas". Se emplazan en lugares de gran control territorial, visualizándose entre sí y visualizando también a la práctica totalidad de los castros indígenas. También aqui observamos una curiosa regularidad, los establecimientos romanos se sitúan en lugares deshabitados, bien sean espacios de escasa o nula capacidad agrícola (Sur del Valle de Lóuzara) o lugares de "posible" significación religiosa (necrópolis tumulares), en cambio en ningún caso encontramos yacimientos romanos en situaciones ocupadas por yacimientos "castrexos". El último rasgo que se puede indicar es que las minas se abren, generalmente, en terrenos con pocas posibilidades de aprovechamiento agropecuario ${ }^{12}$.

Este "modelo estatal» (altoimperial) de ocupación territorial se establece superponiéndose a lo indígena y, una vez finalizada la coyuntura que le dio origen, parece desaparecer sin apenas dejar más huella que los propios yacimientos arqueológicos, es decir, parece ser un modelo sin continuidad temporal, un modelo fosilizado en el paisaje. Es un acontecimiento que no trascendió a los individuos que lo protagonizaron, y por tanto no puede ser calificado como aculturación (LÉVI-STRAUUS 1983: 54).

En torno a finales del siglo III parece empezar a consolidarse un nuevo "modelo" de ocupación del espacio que tiene muy poco que ver con el "modelo estatal» que acabamos de esbozar. A diferencia de éste serán iniciativas privadas las que promuevan las villae, establecimientos encaminados a satisfacer intereses más particulares. Las villae tienen la misma situación fisiográfica que los castros, pero diferente emplazamiento ${ }^{13}, y$

12 Lo cual no implica la intencionalidad de este hecho, ya que el oro en yacimientos primarios aparece en mayor porcentaje en las zonas falladas o muy plegadas. Estas caracteristicas geológicas provocan un relieve muy abrupto donde es más difícil realizar actividades agropecuarias.

13 Para evitar posibles malentendidos quizá sea preciso indicar la diferencia que en este texto se hace entre situación y emplazamiento. Según la clasificación de Linton la situación 
eligen terrenos aptos sobre todo para el labradio, que se hallan bien comunicados, y cercanos a la vía Lucus-Dactonium. Tradicionalmente la arqueología ha admitido que este "modelo" se produce por la descomposición del mundo romano, y se correspondería con una época decadente, con el fin de un período; sin embargo, en este trabajo se defiende que es precisamente con este "modelo innovador" que tanto las villae como los vici se convierten en fundadores, en el punto de partida, de un modelo de hábitat o de ordenación del territorio que tendrá continuidad hasta principios del siglo $x x$.

\section{LA CAIDA DE LAS MURALLAS Y LA LLEGADA DE CRISTO}

Durante siglos la "Cultura Castrexa" se reprodujo, se perpetuó; y sin embargo, esa continuidad acabó por quebrarse para dar paso a nuevas formas de ocupación del espacio, a un nuevo paisaje de poblados abiertos. Podemos denominar en estas líneas como "Modo Antiguo" al sistema de reproducción secular, frente a "Modo Renovado", o la eclosión de una nueva forma de habitar y de edificar el territorio. Autores como Xulio Carballo Arceo (1989) han documentado en la comarca del Deza (Galicia central) lo que puede ser una explicación al hecho de que los castros de épocas anteriores al siglo $\|$ a.C. sean todos de dimensiones más bien reducidas, por lo general inferiores a $1 \mathrm{Ha}$. No se observan en este momento poblados de mayor extensión, como sucederá en épocas posteriores en hábitats como Briteiros o San Cibrán de Las, o el mismo Coaña. La inexistencia de poblados de mayor tamaño contrasta aparentemente con las necesidades de acoger a una población en aumento, población que en ocasiones lleva siglos habitando el lugar; esta «necesidad" derivada del crecimiento de la población se soluciona en la zona estudiada por Xulio Carballo con la "creación de nuevos poblados", es decir, el poblado no crece a la par que la población que contiene, no se documentan en esta época sucesivas ampliaciones de las fortalezas. Este hecho creemos que es importante porque establece un modo de "Reproducción del Presente", es un mecanismo de «Reproducción Cultural». Este modo de "reproducirse" implica que se proyecte el pasado sobre el futuro, se establece una homologación entre pasado y futu-

es "la unidád menor de la región topográfica" y viene definida como "el lugar estructuralmente minimo del relieve (...) mayor al emplazamiento y menor a la fisiografía". Por su parte, el emplazamiento viene definido por Linton como ala localización precisa del espacio construido en sus relaciones con el relieve local. Hace referencia a un espacio más reducido que la situación, por lo que, a veces, una misma situación es aprovechada por dos o más ciudades”. 
ro que implica negar el cambio y hace hincapié en el "Modo Antiguo" porque lo que "ha de ser" se copia de lo que "ha sido y todavía es", es decir, se establece un presente continuo circular. Este modo de reproducción cambiará más adelante, como tendremos ocasiones de ver.

El «Modo Antiguo» alberga otro aspecto que también será importante considerar. Durante este momento se constata el hecho de que nadie vive fuera de las murallas, es decir el hábitat se organiza en poblados comunitarios, amurallados y aislados del entorno por un espacio ideado y construido para impedir el acceso a aquellos no autorizados. Es una fortaleza que se percibe al exterior como una unidad, dentro de esta unidad amurallada existen edificios pertenecientes a los grupos familiares, parece estar claro que se establece una subordinación de la "casa" al poblado. Estos son dos aspectos de lo que en este texto se denomina "Modo Antiguo".

Llamaremos «Modo Renovado» a las situaciones, acciones y comportamientos estructurales que supongan una diferencia con respecto al "Modo Antiguo", y que además impliquen la negación del mismo.

Un primer rasgo del "Modo Renovado", que supone un cambio con respecto a lo que hasta entonces era la norma, es la aparición de los grandes poblados. Aunque su inicio puede arrancar del siglo ॥ a.C., será durante el cambio de era y el siglo । d.C. cuando esta tendencia alcance su equilibrio. Este tipo de yacimientos de varias Has. se hallan mejor representados en la zona portuguesa y orensana que en el resto den NW, donde no están del todo ausentes como lo prueban yacimientos como O Coteirón dos Castros (Toques, A Coruña) (PENEdo y Rodríguez 1991: 206) y otros similares. Estas fortalezas de gran tamaño suponen una censura en el modo en el que se articula la reproducción de la cultura, y entre otras consideraciones pensamos que implica un cambio en las relaciones de poder dentro de la comunidd. Sin embargo, es necesario indicar que este tipo de yacimientos está del todo ausente en la zona que estamos considerando, por lo que abandonaremos aquí este tema.

Lo que se aprecia con más claridad en los yacimientos castrexos de la cuenca del río Sarria son unas pequeñas ampliaciones o "antecastrox» ${ }^{14}$ donde aparece ese material tardio al que se ha hecho referencia con anterioridad, material que también aparece en ocasiones fuera del recinto amurallado. Estas ampliaciones, seguramente debidas al aumen-

\footnotetext{
14 Como dato curioso indicar que los vecinos de la aldea de Pascais denominan "Caricias" a este tipo de estructuras.
} 
to de la población que hacen que el castro se agrande, junto con el material doméstico de época "tardía" hallado fuera de la fortaleza, suponen un cambio drástico, pues el pasdo deja de ser el modelo a cumplir como proyecto de futuro, se abandona el "Modo Antiguo". El poblado ya no es un lugar de habitación colectiva, pues hay parte de esa colectividad que ya no vive en él, sino que se ha creado algo que podriamos llamar un vicus que en estos casos documentados estaria inmediato al castro. Nos hallamos ante la ruptura del "Modo Antiguo" y el inicio de un «Modo Renovado" (que cristalizará en lo que hoy denominamos "paisaje tradicional gallego"). Este acontecimiento acaece entre los siglos IV y VI, consideraremos de modo instrumental el siglo $v$ como el momento de este lento cambio.

Esta especie de "fase terminal" del mundo fortificado de la Edad del Hierro es simultánea al proceso de aparición de villae bajoimperiales, que se documentan ahora en la cuenca del río Sarria (dos de ellas pueden ser San Antolín das Cercas (ARIAS VILAS 1980: VIII) y Vilar de Sarria). Situaremos, a modo de referencia, el momento de aparición de este nuevo modelo de ocupación del territorio, de tradición romana y "Urbana", a comienzos del siglo IV; anterior por tanto a los materiales más tardíos documentados en los castros.

La instalación de élites poderosas y "romanizadas" en el rural supone la emergencia de un nuevo centro de Poder, un poder individual, visible e individualizable en el possessor de la villa. Es un poder económico, politico y militar que se inscribe en el marco de este "Modo Renovado", una realidad para la cual no existe referente indigena. Es un modelo triunfante que se contrapone al modelo en crisis definitiva del mundo Castrexo, del "Modo Antiguo". Es también la alteración de la estructura tradicional de Poder. Sin embargo, esta nueva "realidad triunfante" que observan los "castrexos" no es más que un ingrediente, quizá un simple agente, del proceso de aculturación que los convertiría con el paso de los siglos en campesinos cristianos altomedievales. El ingrediente fundamental de la combinación creemos que es el cristianismo, y en concreto el priscilianismo que se expande por el rural de Galicia, sobre todo tras la muerte de Prisciliano (385-387), quien fue considerado santo en vida y mártir una vez muerto ${ }^{15}$, y cuya doctrina todavía era objeto a

15 En la Crónica de Sulpicio Severo, escrita en el 400, se puede leer: "Muerto Prisciliano no sólo no se reprimió la herejia que habia surgido con su obra, sino que, fortalecida, se propagó aún más ampliamente, pues sus seguidores, que antes lo honraban como santo, después comenzaron a venerarlo como mártir. Los cuerpos de los ejecutados fueron conducidos a España y sus funerales fueron celebrados con grandes exequias" (Tomado de LóPEZ PEREIRA 1989: 42). 
tratar en el primer concilio de Braga del 561 , y pervivia como "poco más que un recuerdo" en el siglo VII (CHADWICK 1978: 302).

Entramos así en lo que se denomina "Época Paleocristiana". Los más antiguos testimonios arqueológicos paleocristianos en Galicia se hallan en la provincia de Lugo, no muy distantes de nuestra zona de estudio.

La evidencia más antigua la constituye la tapa de mármol de un sarcófago paleocristiano de época constantiniana, datado entre 320 y 330 (Schlunk, 1977: 195) que fue hallado en Santa María de Temes (Carballedo, Lugo). En las inmediaciones de la iglesia existe una villa bajo-imperial. El Ilamado Crismón de Quiroga es una mesa de altar circular elaborada en mármol local (procedente del ayuntamiento de Samos o de sus inmediaciones), que se hallaba en la capilla de Nosa Señora da Ermida (Quiroga, Lugo) ${ }^{16}$, donde también existen basas y capiteles de mármol tardorromanos. Este altar tiene una inscripción 17 de resabios priscilianistas (SCHLUNK 1977: 199, 202-203), o cuando menos "poco ortodoxos" (DIAZ Y DíAZ 1991: 175).

En opinión del profesor Díaz y Diaz existen dos momentos en el proceso de cristianización, de ellos el inicial corre a cargo de los grupos priscilianistas, los cuales tienen un papel fundamental en la difusión y asentamiento del cristianismo (DíAz Y Díaz 1991). Aunque se parte de bases anteriores, en torno al siglo III, será en la segunda mitad del siglo

16 La antigüedad de ambas iglesias no sólo viene refrendada por sus hallazgos, sino que la advocación de ambas a Santa Maria, o a la Virgen, es también un indicio de antigüedad. Según el profesor Diaz y Díaz (1976: 247-248) el Convento Lucense posee numerosas titulaciones de iglesias "que parecen haber sido preferidas en época antigua"; asi se observa que en el convento lucense Santa Maria acapara el 20,34\%, la siguen San Pedro con $8,48 \%$, Santiago con $8,16 \%$, San Martín de Tours con $6,87 \%$, San Juan con $6,01 \%$ y Santa Eulalia con $5,31 \%$. De esta lista habria que excluir a Santiago, cuya devolución es posterior al "hallazgo" de su sepulcro en Compostela, y el de San Martín de Tours, pues fue expandido en el siglo vi por San Martin de Dumio. Según el profesor Díaz y Diaz, Santa Eulalia demuestra relaciones con Lusitania, y en conjunto se aprecia la gran antigüedad de estas devociones. Estas advocaciones se repiten casi idénticamente en la zona de estudio considerada en este trabajo y en los ayuntamientos limitrofes. Se realizaron los cálculos no sobre el total de los lugares de culto, sino sobre las iglesias parroquiales, lo que sin duda distorsiona en alguna medida la situación real, pero es sin embargo suficientemente significativa. Se consideraron para el cálculo los ayuntamientos de Samos, Sarria, O Incio, Triacastela, Láncara, Folgoso do Caurel y Pedrafita do Cebreiro, con un total de 157 parroquias. Los resultados fueron los siguientes: Sana Maria 17,83\%, San Juan *,92 \%, San Pedro 8,28 \%, Santiago 7,64 \%, San Martín de Tours 7,01\%, Santa Eulalia cuenta sólo con el 3,18 \%, y con mayor porcentaje que ella están El Salvador con $5,09 \%$ y San Julián, San Esteban, San Miguel y San Vicente $(4,46 \%)$.

17 AVRUM VILE TIBI EST ARGENTI PONDERA CEDANT - PLUS EST QVOD PROPRIA FELICITATE NITES (“El oro es vil para ti, las riquezas de plata abátense, más es lo que brilals por tu propia felicidad’, traducción de SCHLUNK 1977: 199). 
Iv cuando la cristianización arranque con fuerza de la mano de Prisciliano y sus seguidores, finalizando este primer momento aculturador a finales del siglo vi; ya que será en la segunda mitad de ese siglo cuando llegue al NW San Martín de Braga o de Dumio, artífice de la conversión al cristianismo de los Suevos y puntilla definitiva del priscilianismo (DiAz y DiAZ 1976). San Martín de Dumio fue un gran animador del monacato, y de esa época data el monasterio de Samos, erigido en un lugar idóneo para eremitas (ARIAS, M. 1981: 278) y posteriormente el de San Martiño de Lousada (Samos). El priscilianismo tuvo gran repercusión en el monacato galaico, y cuando San Martín de Dumio emprende su labor monástica se empeña también en apagar los últimos brotes de priscilianismo (López Pereira 1989: 61; Chadwick 1978: 291-299).

En nuestra opinión será ahora, entre mediados del siglo iv y mediados del vi cuando se produce el cambio cultural, cuando sobreviene el fin de una cultura y comienza otra nueva. Si bien no podemos decir que los pobladores del área centroriental de Lugo, de lengua y religión célticas, perdiesen sus señas de identidad cultural a causa de la conquista y ocupación romana, algo muy diferente sucede ahora, cuando lo anterior se sustituye por algo sustancialmente distinto, es el paso del «paganismo céltico" a la cristianización y a la latinización. Como se ha expuesto anteriormente, lo romano estuvo socialmente representado, pero no llegó a arraigar culturalmente, sin embargo ahora el cristianismo enraizará profundamente en toda la Gallaecia. "A partir de la segunda parte del siglo vi prevalece una pastoral cristiana de polémica y condena de los usos y prácticas antiguos a través de lo que se llama "demolatría". Es el choque frontal entre lo nuevo y lo viejo. Con la particularidad de que la nueva religión no sólo ofrece un Dios nuevo, un culto y símbolos nuevos, sino que además se presenta como una nueva visión del mundo, de las cosas, de la vida y sociedad humana, con unos principios de estructuración social que tienden a cancelar todo lo anterior. Pues bien, este choque tiene precisamente lugar en torno a la figura y obra de Prisciliano" (FERnández Ardanaz 1990: 209).

En opinión de Novoa Portela y Pérez Cañamares, cuando en el 342 Constantino hace de la Iglesia Católica la religión oficial del Imperio no es porque la mayoría de los súbditos sean cristianos, sino «porque los terratenientes tenían ya fuerza suficiente para imponer y demostrar al Estado que la organización, la ideologia y la dirección política de la Iglesia eran necesarias a la gestión política del Imperio" (NovoA y PÉREZ 1990: 23). En el NW la cristianización será básicamente una labor de priscilianistas, es un cristianismo "herético" y por lo tanto opuesto a la oficialidad que se representaba en las urbes, centros del poder imperial, lugares «romanizados» donde los obispos y el clero irán convirtiéndose en el 
sustituto de un Imperio decadente, se van mutando en funcionarios que ejercen un poder señorial (CHADWICK 1978: 246-248). Frente a ellos están los priscilianistas, cuyos obispos y sacerdotes son guias espirituales y "Santos Varones", que no tienen reparos en sincretizar y cristianizar cultos anteriores, y así la liturgia de Prisciliano resultaba mucho más cercana a los ritos y gestos de los indigenas paganos (FERnández ARDANAZ 1990: 224). Por otra parte, las bases de la difusión y arraigo del Priscilianismo son formas de corte rural, de una organización muy similar a la monástica (PLÁCIDo 1990, 204), señalándose que el propio Prisciliano tenia amigos entre los possessores de las villae, segmento social del cual él provenía. En el rural la vía de entrada del cristianismo fue el priscilianismo, primero a través de las villae, cuyos possessores encontraban en él un modo de oposición al poder urbano episcopal, que se anunciaba como heredero del poder de Roma, pues esta doctrina justificaba la «oposición frontal a la jerarquía (eclesiástica) establecida (...) y había también en ellos un rechazo, más o menos completo, de la sociedad y de la autoridad civil’, (DiAZ y DiAZ 1991: 171-172). Desde estas villae, y por preocupación doctrinal de los priscilianistas, el cristianismo se extiende al rural. El carácter ascético y rigorista del priscilianismo lo acerca al monacato ${ }^{18}$, y la relación entre comunidades ascéticas que se reúnen en conventus o "conventículos" (Díaz MARTínez 1988) para celebrar estas prácticas y las villae es un factor más que posibilitará la transformación de la "villa" en monasterio cuando la doctrina de San Martín de Tours, transmitida por Sulpicio Severo, se difunda por el NW (PLÁCIDO 1990: 203).

En este punto conviene recordar la famosa "estela» de Vilar de Sarria. Según el profesor Acuña Castroviejo, «no existen elementos claramente probatorios de que la escena grabada en el reverso de la estela de Vilar de Sarria sea una representación del mito de Ulises y las Sirenas",m aunque sí que posee un "nítido sentido funerario: una embarcación que guía al difunto al más allá" (ACUÑA 1976: 112). Por nuestra parte, creemos que la representación de la estela es una adaptación del mito clásico, ya que "Ulises y su viaje fueron adaptados por el cristianismo, y desde lo romano tiene una significación funeraria importante" (ACUÑA 1976: 112).

18 Según Díaz Martínez, estas comunidades se diferenciarian del monacato "por su condición no permanente y (...) por la ausencia de una vida en comunidad" (DiAz MARTínez 1988: 213). Según Chadwick no se trataba de comunidades organizadas bajo una regla ni con un hábito especial a los que se les pida vivir permanentemente en casas separadas, sino grupos de varones y mujeres, y también grupos mixtos, que se retiran en períodos limitados de tiempo, sin que se aparten de la normal vida sacramental de la Iglesia. Esto se debe al convencimiento de Prisciliano de que la ambición de poder es incompatible con la humildad monástica (CHADWICK 1978: 30). 
También Castro Nunes nos dice que la representación puede ser datable, en base a la indumentaria, en los siglos III-IV, y que posiblemente sea una representación cristiana (CASTRO NUNES 1958). Por todo lo aducido creo que no se debe desdeñar la hipótesis de que la pareja grabada en el anverso de esta estela fuesen personajes cristianos que habitaban la "villa" de Vilar de Sarria.

\section{LAS ALDEAS CRISTIANAS}

Nos situamos ya en otra realidad, el modelo de hábitat fortificado ha desaparecido; ahora se habitan aldeas (vici, villae vel villares) que aparecerán citadas en el Tumbo de Samos, cuyos documentos se datan mayoritariamente desde la segunda mitad del siglo $\mathrm{x}$ hasta finales del XI. La cita de lugares está, obviamente, mediatizada por la producción de documentos, lo que provoca el carácter "aleatorio" de su cita. A pesar de ello creemos que el poblamiento que hoy denominamos "tradicional" estaba ya formado en esta época, y que arranca de la situación que se ha tratado en líneas anteriores, es decir: el "poblamiento tradicional" parte de la aculturación sufrida por los habitantes de los castros a expensas de la nueva religión, el cristianismo, que implicó un cambio ideológico global, y por ende una mudanza en el patrón habitacional. A modo de hipótesis se podrá indicar el siglo $v$ como catalizador de esta tendencia y el vi como consolidación de la misma, especialmente referido al marco espacial en que se centra este trabajo, es decir, a los ayuntamientos actuales de Samos y Sarria y las zonas limitrofes con ellos. Así en el siglo VII el paisaje de la cuenca del río Sarria estaría ya exclusivamente articulado en función de núcleos rurales abiertos (villas y monasterios), y con una distribución general de los espacios similar a la que se tiene por tradicional para esta zona ${ }^{19}$.

El nacimiento de estas aldeas cristianas es el fruto de un proceso complejo y prolongado de cambio cultural que, en última instancia, se significa en la mudanza de todo un cúmulo de acontecimientos que se han ido tratando anteriormente; al lado de ellos hay que considerar otros dos aspectos no mencionados todavia y que no abordaremos más que de modo superficial en estos párrafos: la desaparición total del poder imperial romano y su sustitución por el Reino Suevo y el nacimiento del gallego como lengua romance, y por tanto diferenciada ya del latín.

19 Sobre las características de este paisaje ver BoHIER, A., 1979: 376-405. 
Ambos aspectos confluyen en la explicación y datación de los topónimos mayores que derivan de antropónimos germanos. A este respecto es de reseñar que el $23,2 \%$ de los topónimos mayores de esta zona, incluyendo en el recuento tanto los hábitats actuales como los deshabitados medievales, derivan de antropónimos de possessores germanos ${ }^{20}$. Esta clase de topónimos se convierten en útiles para datar el momento de aparición de aldeas actuales, ya que establecen un segmento cronológico bastante determinado. Nos estamos refiriendo a los topónimos que acaban en -an, -e e -iz como por ejemplo Gontán, Aïán, Nande, Freituxe, Gundriz o Estraxiz. Todos ellos proceden del genitivo que señalaba la posesión sobre una villa, como sería Villa *Gondani, Villa Nandi o Villa Astragis ${ }^{21}$. Para que estos topónimos se produzcan es preciso que se utilice una lengua declinada o que al menos conserve restos de la declinación latina, es necesario que se conserve el genitivo en el habla común para que se produzca este modelo toponímico tan fructifero en el NW peninsular, y obviamente, es imprescindible que exista una persona que lleve tal nombre germano. Estas características de antroponimia germánica y lengua tardolatina con flexión se corresponden con los siglos $v \mathrm{y} \mathrm{vi}{ }^{22}$, por lo que el elemento designado por el topónimo tendrá una cronología análoga. Esta datación puede ser "afinada" si consideramos que el dominio suevo sobre Galicia se hará realmente efectivo e importante tras su derrota a manos visigodas y el desplazamiento al norte de Gallaecia de la influencia sueva; momento que se data durante la monarquía de Remismundo, que reina desde el 460; sin embargo, ya desde antes los galaicos del norte (actual Galicia) colaboraban con los suevos en los saqueos e incursiones sobre el resto de Hispania (BALIÑAS PÉREZ 1991), por lo que es probable que desde muy pronto hubiese possessores germanos que podian dar nombre a sus villas; aunque sea a partir del 460 , al producirse una verdadera presencia del poder suevo, cuando debamos datar estos topónimos.

20 La repartición porcentual según el origen de los topónimos de la zona se efectúa como sigue: el 25,6\% proviene de nombres propios en genitivo, ya sean antropónimos germanos o latinos, aunque con casi total exclusividad de aquéllos sobre éstos. El $53,7 \%$ de los topónimos son descriptivos, entre ellos hemos difereniado los que describen aspectos fisiográficos $(8,9 \%)$, de los que se refieren a edificaciones y caminos $(24,1 \%)$ y los que designan elementos naturales del paisaje $(20,7 \%)$. Derivados de nombres de santos tenemos el $9,4 \%$, y finalmente topónimos que hacen referencia a otros aspectos o que no se ha podido establecer su relacion es el $11,3 \%$.

21 Para más detalles sobre estos étimos consultar Piel \& Kramer (1976), Gontán 145/44a, Aián 5/16, Nande 191/10, Freituxe 271/34, para -tuxe, más 106 para Frei-, Gundriz 145/28, Estraxiz 27/5.

22 Agradezco a los profesores Juan J. Moralejo y A. Santamarina su ayuda desinteresada y sus valiosas apreciaciones e indicaciones en lo referente a estos aspectos del Cambio Cultural. 
Como se ha expuesto con anterioridad, detrás de la aparente dife'rencia radical entre ambas formas de construir el paisaje y de ubicarse y ordenar el espacio, existen semejanzas entre el hábitat fortificado de época castrexa y el hábitat abierto cristiano, concretada sobre todo en el emplazamiento y situación de los hábitats con respecto a los dominios agrícolas de tierras frías y calientes, de monte y de labradíos. Si observamos los castros de la zona de estudio y rastreamos en cuanto hubo una continuidad del hábitat en época "altomedieval», observaremos lo siguiente:

1. Mantenimiento absoluto del hábitat. La aldea (ahora abierta) se construye sobre el castro: Vila do Castro (fig. 5), Castrelo y quizás Gundriz, todos en el Valle del Lóuzara (8,6 \%).

2. Establecimiento (o mantenimiento) del hábitat inmediato al castro, es decir, con idéntico emplazamiento. Se diferencia del castrexo porque la aldea crece "extramurallas": Seteventos, Loseiro, Allariz, Loureiro, Lourido, Calvor, Petos de Mourelle, Castelo dos Infantes, Aián, Escanlar, Santa Marta de Castroncán y San Román (34,2\%).

3. Se mantiene la situación fisiográfica, pero se varía el emplazamiento, la aldea se sitúa en las proximidades del castro, siempre dentro de la misma situación fisiográfica: Mondín, Estraxiz, Nande, Romelle, Pascais, Devesa de Ribas, As Perais, Bustofrío, Os Castros y Golado (28,6 \%).

4. Abandono definitivo de la situación fisiográfica: Santa Icía, San Antonio, San Cosme (fig. 6), Foral, Margarita, Parada, Castrofeito, Casa dos Mouros, Formigueiros y Moura (28,6 \%). Este grupo incluye todos los yacimientos fortificados romanos vinculados con la actividad minera. Obsérvese también que en cuatro de estos diez yacimientos se construyó en época altomedieval una capilla.

Estas cifras, de carácter meramente indicativo y sin valor definitorio, apuntan hacia una perduración del hábitat a modo de "fósil». En total, el $71, \% \%$ tienen continuidad habitacional frente al $28,6 \%$ restante, cuyo modelo de ocupación del territorio se reveló inadecuado a los nuevos tiempos (o ya antes), su concepción estructural era incompatible con el "Modo Renovado". Este 28,6 \% (a excepción de uno de ellos) está formado por la mayoría de los yacimientos que a la hora $d$ escoger su emplazamiento, en el momento de su construcción, antepusieron las condiciones defensivas a las agricolas. Como se ha indicado, esta herencia se observa no sólo en las aldeas que "descienden" directamente de los castros, sino también en aquellas otras que fueron edificadas en solares antes deshabitados, ya que éstas mantuvieron férreamente el patrón de emplazamiento castrexo en lo referente a su situación relativa con respecto al monte y al labradio, a las tierras frías y las calientes, así pues 

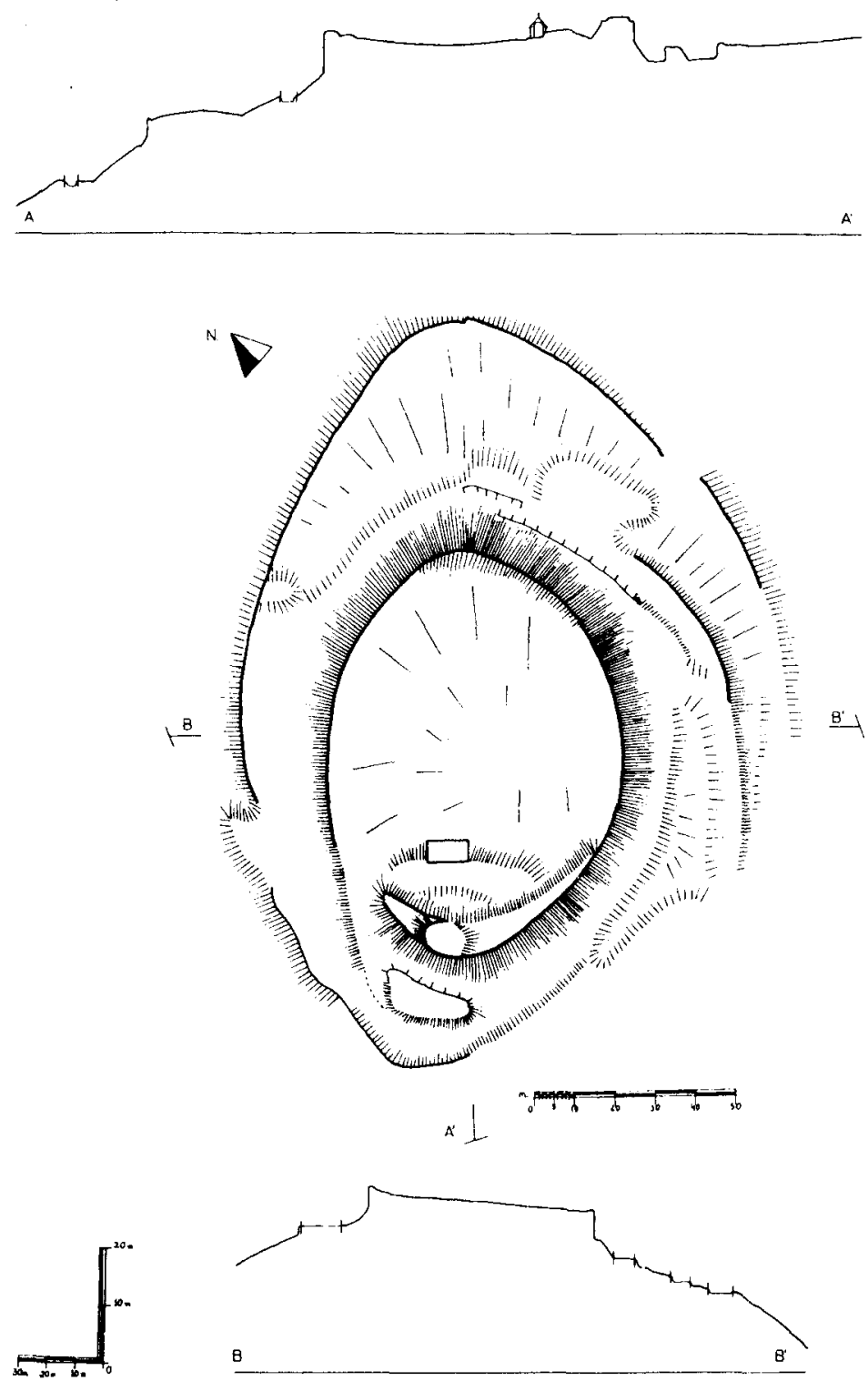

Fig. 6. Castro de San Cosme, yacimiento en el que se produce un abandono total de la habitación, pero pervive como lugar de culto. La linea gruesa continua indica los tramos de muralla visible. Obsérvese la capilla tanto en el corte como en la planta. 
"se puede comprobar que el poblamiento medieval mantiene las tendencias básicas ya inscritas en el poblamiento castreño, y lo único que hace es reforzarlas" (CRIAdo 1989: 91).

Si revisamos la ubicación de los centros de poder de época altomedieval que aparecen en la documentación escrita de la época, se observa que el «lugar central" se corresponde con antiguos castros de la Edad del Hierro. Se puede registrar una vinculación entre los condados y territorios civiles citados por la documentación medieval más antigua y yacimientos castrexos concretos; a saber: el Condado de Parada, en el valle de Lóuzara, se podrá relacionar con A Roda do Castro de Parada, hábitat fortificado de creación romana; Condado de Loseiro, en relación con el castro de idéntico topónimo; Condado de Froián, en cuyo centro están Os Castros de Castelo. En un territorio de carácter eclesiástico, en el Territorio Lausata se edificó probablemente en el siglo vi, inmediato al castro de San Román, el monasterio de San Martiño de Lousada, en cuyo "territorio" se hallaba el mismo monasterio de Samos. Otros lugares de culto cristiano relacionados con castros son el Castro de Calvor, donde se halla la iglesia parroquial, y que por un documento del 24 de abril del año 785 sabemos que se denominaba "Astorica» y que inmediato a él estaba la villa Calvaria, donde se erigió un monasterio al lado de una iglesia anterior. Otras iglesias parroquiales en castros o inmediatas a ellos están en Seteventos (donde existen, igual que en Calvor, elementos arquitectónicos "visigóticos" reutilizados0, Loureiro y Santa Marta de Castroncán. En San Cosme (fig. 6), en San Antonio, y posiblemente en Santa Icía y Margarita, existen o existieron capillas en las que se celebraban romerias.

\section{CONSIDERACIONES FINALES}

A lo largo de estas páginas se ha intentado mostrar una serie de acontecimientos históricos (fig. 7) que considerados en conjunto, y en el contexto de una zona geográfica concreta como es la cuenca media del río Sarria, pueden aportar un punto de vista diferente, o al menos tienen la virtud de "pretender atentar" contra la fragmentación del saber que se observa entre las disciplinas que estudian, o que pueden estudiar, una misma realidad; en este caso el proceso de cambio cultural que funda la sociedad tradicional (que hoy estamos a punto de liquidar). Esto se concreta en el final estructural de la Edad del Hierro, la "romanización», cristianización y latinización; diversas caras de un mismo poliedro.

De todas estas líneas se derivan una serie de hipótesis, todas ellas apuntan ai siglo v como momento central del Cambio Cultural, aunque 


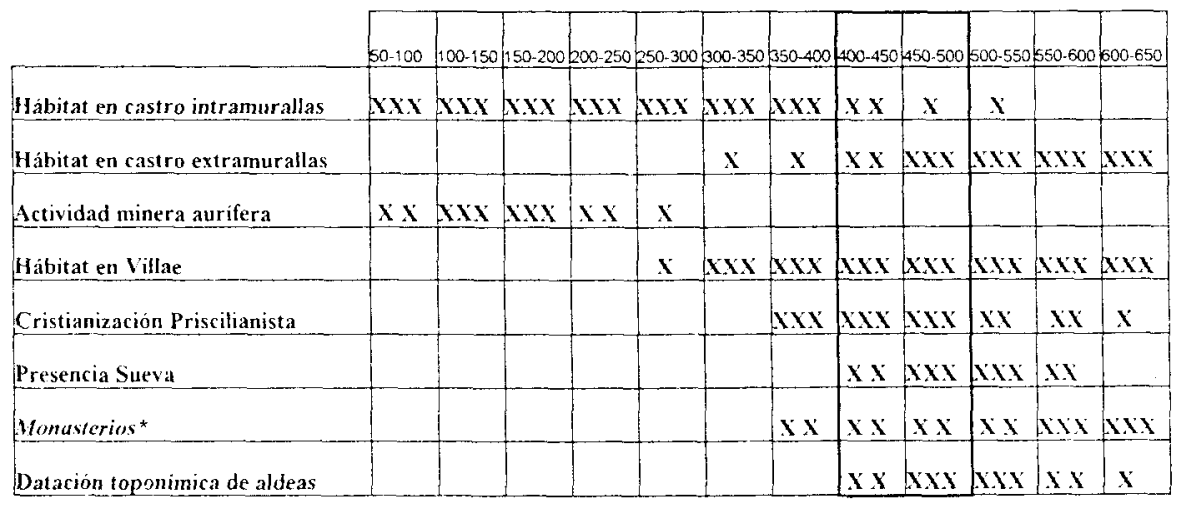

* Se unchyen aqui los comrentula prisciliantastas

Fig. 7. Cuadro que muestra la distribución temporal de los acontecimientos históricos citados en el texto.

éste debe ser considerado como un proceso prolongado y complejo que abarca desde principios del siglo iv al siglo vil.

Se observa en esta zona que se produce un mantenimiento estructural del poblamiento y del mundo castrexo hasta el siglo $v$, momento éste en el que se documentan ocupaciones en las inmediaciones de algunos castros. Hasta entonces la presencia romana, socialmente representada en esta comarca, se había limitado a la explotación de los recursos auriferos y a asegurar y controlar militarmente sus infraestructuras, aunque esta actividad difícilmente se pueda llevar más acá del siglo III d.C. Será precisamente a finales del siglo III, con más seguridad en el IV, cuando se debilita el poder imperial y surgen las villae; con ellas se extiende una nueva forma de concebir el mundo que tendrá gran éxito: es el cristianismo que, merced al priscilianismo, logra suplantar, aunque sea sincréticamente, a una religión céltica que sustentaba ideológicamente una forma de vida ya en crisis. Asi el fin del mundo castrexo no parece que venga dado por la "romanización", sino por la cristianización, por una aporte ideológico que supone el final de una tradición que hemos querido denominar "Modo Antiguo".

Con el abandono de los castros surge la aparición de vici, que serán las futuras villas y casales de la documentación medieval. También ahora 
surgen los primeros monasterios en la zona, los clérigos acabarán por arrebatar el poder a los nobles suevos.

Estos nuevos "modos" de habitar, este cambio, supone la continuidad del modelo agrícola y de ocupación general del espacio que estuvo vigente durante la Edad del Hierro; emerge el embrión del paisaje tradicional de Galicia.

Finalmente se puede indicar que el proceso aquí ejemplificado, a partir de las evidencias disponibles en esta zona en concreto, es probable que ilustre una realidad más general en el NW peninsular. Tal vez determinadas áreas costeras y zonas urbanas o periurbanas posean dinámicas distintas a la que se ha trazado en las líneas precedentes; sin embargo, la hipótesis que aquí se defiende, dada la entidad de los argumentos y acontecimientos históricos de carácter más general que se han manejado, y por lo que se puede entrever en diversos estudios ${ }^{23}$, podrá ser aplicable a la mayor parte del ámbito rural del NW hispano.

\section{RESUMEN}

Partiendo de las evidencias históricas proporcionadas por la investigación arqueológica y antropológica que llevamos a cabo en la zona centro-oriental de la provincia de Lugo; y por medio de su contextualización dentro de los acontecimientos históricos observados en su entorno cultural, se aborda el estudio de la desaparición del hábitat fortificado de la Edad del Hierro y su sustitución por aldeas abiertas. Se analiza someramente el mundo de la Edad del Hierro en esta zona y la incidencia estructural de la conquista romana, buscando en ella rasgos del cambio cultural. Se trata el proceso de cristianización, con especial mención a la doctrina priscilianista. La construcción del discurso se concibe contra la fragmentación del saber en diversas disciplinas que estudian facetas diferentes de una misma realidad cultural.

23 En la comarca de Terra de Trasdeza (Silleda, Pontevedra) se puede observar un comportamiento muy similar, tal y como apunta Carballo Arceo y como puede deducirse, desde nuestro punto de vista, de las evidencias publicadas por este autor (CARBALLO ARCEO 1986: 127-136, y sobre todo 141-144). En la provincia de A Coruña, ayuntamientos de Toques y Melide, el área Bocelo-Furelos (CRiAdo BoADo et al. 1991) proporciona igualmente evidencias en este sentido. En la cuenca del río Boeza (El Bierno, León) también se observan toda una serie de rasgos concordantes con esta hipótesis (RODRIGUEz FERNÁNDEZ 1991a). Del mismo modo en áreas próximas al NW como en la vertiente leonesa de la Cordillera Cantábrica se observa un proceso semejante (GUTIÉRREZ GonZÁLEZ 1985). 


\section{ABSTRACT}

Basec on historical evidences derived from our archaeological and anthropological review in central eastern Lugo (in Galicia, NW Spain), and because of their inclusion in the historical an cultural context of Galicia, we are studyin the phenomenon of the end of the Iron Age and the emergence of open villages. The Iron Age in this region and the structural incidence, from different perspectives, of the Roman Conquest, are analysed searching therein for traces of cultural change. The Christianization process, with special attention to Priscilian's doctrine, is also examined. The argument constructed in this paper is conceived against the fragmentation o Knowledge in diverse teachings that study different facets of the same cultural reality.

\section{AGRADECIMIENTOS}

En primer lugar, a mis amigos y compañeros de equipo: Ana Filgueiras Rey, Juan José Perles Fontao, Juan Carlos Castro Carrera y Ángel Acuña Piñeiro; con ellos he compartido y disfrutado del trabajo de campo. A los vecinos de Samos y Sarria por el afectuoso trato que nos han dispensado. A la Comunidad Benedictina del Monasterio de Samos, especialmente al $P$. Pedro de la Portilla por su hospitalidad e interés y al finado P. Maximino Arias, archivero del Monasterio, con quien tuvimos la suerte de mantener largas y fructíferas conversaciones; él nos abrió las puertas de la biblioteca. A Xulio Carballo Arceo, cuyas aportaciones a este artículo son fruto de sus enseñanzas y de las periódicas conversaciones mantenidas a lo largo de estos años. A Juan Naveiro López y a Pepa Rey Castiñeira, por sus valiosas consideraciones acerca de la cerámica. A los profesores J. Moralejo y A. Santamarina, que amablemente me ayudaron en las cuestiones lingüísticas. Finalmente quiero expresar mi reconocimiento tanto a Ana Filgueiras Rey, que ha enriquecido y revisado los contenidos teóricos expuestos en este trabajo (además de soportar con amor la gestación de este artículo), como a Felipe Criado Boado, por el ánimo que me ha infundido y por la valiosa revisión critica del texto.

\section{BIBLIOGRAFIA}

Acuña Castroviejo, F. (1976): "Sobor da Representación do Tema "Ulises e as Sereas" na Estela de Vilar de Sarria (Lugo)", Boletin Auriense, tomo VI, pp. 107-115. Ourense. Almagro Gorbea, M. (1992): "El Origen de los Celtas en la Península Ibérica. Protoceltas y Celtas", Polis 4, págs. 5-31. Alcalá. 
ARIAS, M. (1981): “El Monasterio de Samos desde sus Orígenes hasta el siglo Xi", Archivos Leoneses, núm. 35, págs. 267-350. León.

ARIAS VILAS, F. (1980): "Limiar", en PAZOS GARCIA, D., Apuntes acerca de la historia de la villa y comarca de Sarria. Ensayo Histórico. Ed. Albarello 1980 (1. ${ }^{a}$ edic. Ed. Imprenta Establecimiento tipográfico de Jaime Ratés. Madrid 1916).

- (1992): A Romanización de Galicia. Ed. A Nosa Terra, série Historia de Galicia núm. 2. Vigo.

Baliñas Pérez, C. (1991): "El Reino Suevo de Galicia», Historia de Galicia. Tomo I, Fasc. 10, págs. 177-196. Vigo. Ed. Faro de Vigo.

BENVENISTE, Ė. (1983): Vocabulariod e las Instituciones Indoeuropeas. Madrid, Taurus (Le vocabulaire des institutions indo-européennes. Minuit, 1969. Paris).

Bermejo BarRera, J.C. (1986): "Los Dioses de los caminos", en Mitología y Mitos de la Hispania Prerromana 2, págs. 193-230. Madrid, Akal.

- (1991): Fundamentación Lógica de la Historia. Madrid, Edic. Akal.

- (1993a): «Sobre las Dimensiones Significativas del Espacio», Concepcións Espaciais e Estratexias Terrotoriais na Historia de Galicia, págs. 5-22. AHG. Santiago de Compostela.

- (1993b): “Sobre la Construcción del Objeto Historiográfico. Consideraciones sobre el método de la Historia de la Historiografia", Galicia e a Historia, págs. 7-28. Santiago, Tórculo edic.

BOUHIER, A. (1979): La Galice. Essai Géographique d'Analyse et d'Interprétation d'un Vieux Complexe Agraire. La Roche-sur-Yon (Vemdée), Imprimerie Yonnaise.

BradLeY, R. (1987): "Time Regained: The Creation of Continuity", Journal of the British Archaeological Association, núm. CXL, págs. 1-7.

Carballo Arceo, X.L. (1986): Povoamento Castrexo e Romano da Terra de Trasdeza. Arqueoloxía/lnvestigación 2. Santiago, Xunta de Galicia.

- (1989): A Cultura Castrexa na Bacia Media do Rio Ulla. Tesis doctoral inédita. Santiago, abril de 1989.

- (1990): "Los Castros de la Cuenca Media del Río Ulla y sus Relaciones con el Medio Físico", Trabajos de Prehistoria, vol. 47, págs. 161-199. Madrid.

CASTRo Nunes, J. (1958): “Uma Estela Lucense de Inspiração Neo-Platónica", Zephyrus IX, págs. 234-236. Salamanca.

Clastres, P. (1979): A Sociedade contra o Estado. Investigações de Antropología Política. Edições Afrontamento. Porto (Éditions Minuit, Paris 1974).

Clastres, P.; Gauchet, M.; Adler, A., y Lizot, J. (1980): Guerra, Religião, Poder. Lisboa. Ed. 70 (Libre, vol. 772-2. Payot. Paris 1977).

Coelmo Ferreira da Silva, A. (1986): A Cultura Castreja do Noroeste de Portugal. Paços de Ferreira.

Criado Boado, F. (1989): "Arqueología del Paisaje y Espacio Megalítico en Galicia», Arqueologia Espacial, núm. 12, págs. 61-117. Lisboa-Teruel 1988.

- (1993): "Visibilidad e Interpretación del Registro Arqueológico", Trabajos de Prehistoria, vol. 50, págs. 39-56. Madrid.

Criado Boado, F.; Bonilla Rodriguez, A.; Cerqueiro landin, D.; Diaz Vázquez, M.; Gonzalez Méndez, M.; Infante Roura, F.; Méndez Fernández, F.; Penedo Romero, R.; Rodriguez Puentes, E., y Vaquero Lastres, J. (1991): "Arqueología del Paisaje. El Área BoceloFurelos entre los Tiempos Paleolíticos y Medievales. (Campañas de 1987, 1988 y 1989)", Arqueoloxia/Investigación 6. Santiago de Compostela, Xunta de Galicia.

Chadwick, H. (1978): Principios de Avila. Ocultismo y poderes carismáticos en la lglesia primitiva, Madrid, Espasa Calpe. (Priscilian of Avila. Oxford University Press, 1976).

Davis, W.M. (1954): Geographical Essays. Dover Publications. New York (1. ${ }^{a}$ ed. Ginn \& Co. 1910).

Derruau, M. (1966): Geomorfología. Barcelona, Ariel. (Précis de Géomorphologie, $5^{a}$ ed. revue et mise a jour. Masson et Cie. Paris 1965).

DiAz y DiAz, M.C. (1976): "La Cristianización en Galicia”, La Romanización de Galicia, 105-120. Sada A Coruña. Ed. del Castro.

- (1977): "Origenes Cristianos en Lugo", Actas del Coloquio Internacional sobre el Bimilenario de Lugo, págs. 237-250. Lugo. 
- (1991): "La Cristianización de Galicia», Historia de Galicia. Tomo 1, Fasc. 9, págs. 161176. Vigo, Faro de Vigo.

Diaz Martinez, P. de la C. (1988): “Áscesis y Monacato en la Península Ibérica antes del siglo VI", Actas del I Congreso Peninsular de Historia Antigua. Vol. III, págs. 205-225. Santiago de Compostela.

DumEZIL, G. (1952): Les Dieux des Indo-Européens. Paris, P.U.F.

- (1971): El destinod el Guerrero. México, Ed. Siglo XXI. (Heur et malheur du Guerrier. Paris, P.U.F. 1969).

- (1990): Los Dioses de los Germanos. Ensayo sobre la formación de la religión escandinava. Ed. S. XXI. 2. ${ }^{a}$ ed. México. (Les Dieux des Germains. Paris, P.U.F. 1959).

DuRkheim, E. (1982): Las Formas Elementales de la Vida Religiosa. Madrid, Akal. (Les Formes Élémentaires de la Vie Religieuse. Paris 1914).

Eco, U. (1972): La Estructura Ausente. Barcelona, Ed. Lumen, 510 págs. (La Struttura Assente. Casa Editrice Valentino Bompiani \& C.S.p. A., 1968).

Fariña Busto, F., y SuÁrez Otero, J. (1988): "Arqueoloxía Medieval en Galicia: Unha Aproximación", Trabalhos de Antropologia e Etnologia, vol. 28, fasc. 3/4, págs. 49-77. Porto.

Fernández ARdANaz, S. (1990): “Religiosidad Cósmica y Simbología Pagana en Prisciliano", Cristianismo y Aculturación en Tiempos del Imperio Romano. Antigüedad y Cristianismo VII, págs. 207-235. Murcia, Universidad de Murcia.

Foucault, M. (1988): Las Palabras y las Cosas. Una arqueologia de las ciencias humanas. Madrid, Ed. S. XXI. 18. ${ }^{a}$ ed. (Les mots et les choses, une archéologie des sciences humanes, 1966).

Garcia Fernandez-Albalat, B. (1990): Guerra y Religión en la Gallaecia y Lusitania Antiguas. Sada-A Coruña, Ediciós do Castro.

Garcia Garcia, J.L. (1976): Antropologia del Territorio. Madrid, Taller Ediciones JB.

- (1990): "El Discurso sobre el Espacio y la Identidad Cultural", Actas do Simposio Internacional de Antropoloxia. Identidade e Territorio. Santiago de Compostela, Consello da Cultura Galega, págs. 73-88.

GaRcia QuINTELA, M.V. (1993): "Viriato y la Ideología Trifuncional Indoeuropea", Polis núm. 5, págs. 111-138. Alcalá.

GODELIER, M. (1986): Antropologia y Biologia. Barcelona, Anagrama.

- (1989): Lo ldeal y lo Material. Madrid, Taurus. (L'Idéel et le Matériel. Lib. Arthème Fayard, 1984).

GutierRez Gonzalez, J.A. (1985): Poblamiento Antiguo y Medieval en la Montaña Central Leonesa. León, Excma. Diputación Provincial de León.

Habermas, J. (1989): Teoria de la Acción Comunicativa: Complementos y estudios previos. Madrid, Cátedra col. Teorema. (Vorstudien und Ergänzungen zur Theorie des kommunikativen Handelns. Frankfurt am Main, Suhrkamp Verlag, 1984.

KUHN, T.S. (1993): La Revolución Copernicana. La astronomía planetaria en el desarroIlo del pensamiento occidental. Barcelona, Planeta Agostini. (The Copernican Revolution, Planetary Astronomy in the Develepoment of Western Thougth. President and Fellows of Harvard College, 1957).

LEACH, E. (1989): Cultura y comunicación. La lógica de la conexión de los simbolos. Madrid, Edit. Siglo XXI, $4 .^{a}$ edic. (Culture and Comunication. The logic by which the symbols are connected. Londres, Cambridge University Press, 1976).

LÉvi-Strauss, C. (1973): Antropologia Estructural. Buenos Aires, Eudeba, $5 .{ }^{a}$ ed. (Anthropologie Structurale, Paris, Librairie Plon, 1958).

- (1986): O Olhar Distanciado. Lisboa, Eds. 70. (Le Regard Eloigné, 1983).

López Pereira, J.E. (1989): O Primeiro Espertar Cultural de Galicia. Santiago, Universidade de Santiago de Compostela: Serie Galicia.

Lucas Álvarez, M. (1986): El Tumbo de San Julián de Samos (siglos VIII-XII). Estudio introductorio. Edición diplomática. Apéndices e indices. Santiago de Compostela, Caixa Galicia.

Luzón Nogué, J.M., y Sánchez-Palencia Ramos, F.J. (1980): El Caurel. EAE 110. Madrid, Ministerio de Cultura, 155 págs.

Mañanes Pérez, T. (1981): El Bierzo Prerromano y Romano. León, Caja de Ahorros Monte de Piedad de León y Archivo Histórico Diocesano de León. 
Miller, D., y Tilley, Ch. (ed.) (1984): Ideology. Power and Prehistory. Cambridge University Press.

MonkHouse, F.J. (1978): Diccionario de Términos Geográficos. Barcelona, Oikos-Tau. (A Dictionary of Geography, London, Edward Arnold, 1978).

NAVEIRO LOPEZ, J.L. (1991): “El Comercio Antiguo en el NW Peninsular», Monografias Urxentes do Museu, núm. 5. A Coruña, Ed. do Museu Arqueolóxico e Histórico de A Coruña.

Novoa Portela, F., y Pérez Cañamares, E. (1990): "La Aculturación como Modelo de Transición Social: Los Mecanismos de la Cristianización", Cristianismo y Aculturación en Tiempos del Imperio Romano. Antigüedad y Cristianismo VII, págs. 19-25. Murcia, Universidad de Murcia.

Penedo Romero, R., y Rodriguez Puentes, E. (1991): “La Edad del Hierro: Formas Concretas de Pasado Fortificado. Excavación en área en el yacimiento de Os Castros" (pág. 48), en Criado Boado, F.; Bonilla Rodriguez, A.; Cerqueiro landín, D.; díaz Vázouez, M.; González Méndez, M.; Infante Roura, F.; Méndez Fernández, F.; Penedo Romero, R.; Rodriguez Puentes, E., y VAquero Lastres, J., “Arquelogía del Paisaje. El Área Bocelo-Furelos entre los Teimpos Paleolíticos y Medievales. (Campañas de 1987, 1988 y 1989), Arqueoloxia/Investigación 6. Santiago de Compostela, Xunta de Galicia.

Perles Fontao, J.J. (1991): “Prospección Arqueolóxica do Concello de Oia (Pontevedra)», Arqueoloxia Informes 2. Campaña 1988, págs. 233-236. Santiago, Xunta de Galicia.

PIEL, M.J., y Kremer, D. (1976): Hispano-gotisches Namembuch. Der Niederschlag des Westgotischen in den alten und hentigen Personen- und Ortsnamen der Iberischen Halbinsel. Heidelberg, Ed. Carl Winter. Universitätsverlag, 399 páginas.

PlácIdo SuÁrez, D. (1990): “El Cristianismo y las Mutaciones Sociales del Noroeste Peninsular», Cristianismo y Aculturación en Tiempos del Imperio Romano. Antigüedad y Cristianismo VII, págs. 197-205. Murcia, Universidad de Murcia.

Rodriguez Fernández, T. (1991a): La Proyección ldeológica en el Espacio: Análisis de los Poblados Fortificados Protohistóricos en Tierra Seca (El Bierzo). Trabajo de investigación de Tercer Ciclo (inédito). Santiago de Compostela, septiembre de 1991.

- (1991b): “Prospección Arqueolóxica e Estudio Etno-Cultural do Concello de Samos (Lugo)", Arqueoloxia/lnfores 2. Campaña 1988, págs. 229-232. Santiago, Xunta de Galicia.

SaHLINS, M. (1980): Cultura y Razón Práctica. Contra el utilitarismo en la teoria antropológica. Barcelona, Gedisa. (Culture and Practical Reason. Chicago, University of Chicago, 1976).

- (1988): Islas de Historia. La muerte del Capitán Cook. Metáfora, antropología e historia. Barcelona, Gedisa. (Islands of History, 1985).

Sanchez-Palencia Ramos, F.J., y Pérez Garcia, L.C. (1980): "Las Explotaciones Auríferas y la Ocupación Romana del NW de la Península lbérica", Actas II Sem. de Arq. del NW. Santiago de Compostela, págs. 227-246.

SCHLUNK, H. (1979): “Los Monumentos Paleocristianos de "Gallaecia", Especialmente los de la Provincia de Lugo", Actas del Coloquio internacional sobre el Bimilenario de Lugo, págs. 193-236. Lugo.

Vazouez Varela, J.M., y Bermejo BarRera, J.C. (1991): "La Cultura Castreña", Historia de Galicia, vol. 1, fasc. 5, págs. 81-100. Vigo, Ed. Faro de Vigo.

Veiga Arias, A. (1983): Algunas Calas en los Origenes del Gallego. Vigo, Editorial Galaxia, 305 páginas. 